\title{
Hydrogen Storage Properties and Structure of Magnesium-Based Alloys Prepared with Melt-Spinning Technique
}

\author{
Kazuhide Tanaka
}

Additional information is available at the end of the chapter

http://dx.doi.org/10.5772/50170

\section{Introduction}

Magnesium is known to have a relatively high hydrogen storage capacity of $7.6 \mathrm{wt}$ \% by forming a non-metallic hydride $\mathrm{MgH}_{2}$, and has long been a target of many research works for developing excellent hydrogen storage materials. However, owing to very small hydrogen solubility and diffusivity in metallic $\mathrm{Mg}$, together with very low chemical reactivity of its surface with hydrogen gas, the hydrogenation (and dehydrogenation) rate of $\mathrm{Mg}$ is generally quite slow, and temperatures above $\sim 400^{\circ} \mathrm{C}$ and gas pressures exceeding $\sim 10$ $\mathrm{MPa}$ are required to cause the reaction. Several techniques have been developed to overcome this drawback of $\mathrm{Mg}$ without significantly reducing its hydrogen capacity. Among them, ball-milling and melt-spinning techniques appear to be most important. In the former, commercially available $\mathrm{MgH}_{2}$ powder is mixed with a small amount of transition metal powder (Ti, V, Mn, Fe, Ni, Nb, Pd, etc., and their oxides or fluorides) and ball-milled for appropriate time periods. The mechanically milled powder exhibits an excellent reactivity with hydrogen, absorbing $\mathrm{H}_{2}$ gas even at $\sim 100^{\circ} \mathrm{C}$ or lower temperatures, and desorbing it above $\sim 200^{\circ} \mathrm{C}$. Here, the transition metal additives play crucially important roles by working as chemical catalysts for the abs/des reactions on the surface of micron-size Mg powder (Barkhordarian et al., 2004; Liang et al., 1999; Zaluska et al., 1999). On the other hand, in the latter, $\mathrm{Mg}$ alloyed with small amounts of transition metal ( $\mathrm{Ni}, \mathrm{Pd}$, etc.) and/or rare earth ( $\mathrm{La}, \mathrm{Ce}, \mathrm{Nd}$, etc.) is melt-spun to form a thin metallic ribbon of normally amorphous structure. Upon crystallization, it changes into a stable multi-phase nanostructure where nano-sized grains of the alloying elements or their compounds are homogeneously precipitated in a nano-crystalline $\mathrm{Mg}$ matrix. The ribbon thus produced also exhibits an excellent reactivity with hydrogen. Here, nano-sized precipitates promote the chemisorption of $\mathrm{H}_{2}$ molecules on the ribbon surface and enhance the flow of $\mathrm{H}$ atoms into the interior to form alloy hydrides (Spassov \& Köster, 1999; Tanaka et al., 1999). 
We have studied the hydrogen storage properties and structures of melt-spun and crystallized $\mathrm{Mg}-(\mathrm{Ni}, \mathrm{Pd})-(\mathrm{La}, \mathrm{Nd})$ alloys using several experimental and analytical techniques, and have made clear the absorption and desorption processes of hydrogen in the alloys (Tanaka, 2008; Tanaka et al., 2009; Yamada et al., 2001; Yin \& Tanaka, 2002). In this chapter, some of our results specifically on $\mathrm{Mg}$-Ni-La alloy, in comparison with $\mathrm{Mg}-\mathrm{Ni}$ alloy, are reviewed and desorption mechanisms of hydrogen in these alloys are discussed. This chapter is composed of the following sections. In section 2, experimental procedures for the sample preparation with melt-spinning technique and for hydriding/dehydriding (H/D) measurements are described, and phase structures of hydrogenated/dehydrogenated samples characterized by X-ray diffraction (XRD) are shown. In section 3, equilibrium properties and kinetic behavior of hydrogen in the alloys as revealed by pressurecomposition isotherms (PCT) and H/D rates, respectively, are described. In section 4, thermal desorption spectra (TDS) of samples subjected to various H/D treatments are provided, where component TDS peaks are related with existing hydride phases in the alloy. Section 5 is devoted to transmission electron microscope (TEM) observation of nanostructures of hydrogenated and dehydrogenated samples. High-resolution TEM (HRTEM) combined with electron energy-loss spectroscopy (EELS) is used to identify the metallic and hydride phases in the samples. An EELS plasmon peak (H-plasmon) of $\mathrm{MgH}_{2}$ is successfully used to visualize the formation and destruction of the hydride phase in the sample. In section 6, the H-plasmon peak is applied to an in situ observation of the desorption process of the $\mathrm{MgH}_{2}$ phase during heating. Finally, in section 7, concluding remarks are given, where the importance of the role of nano-grain boundaries as pathways of hydrogen flowing into and out of the nanostructured alloy is emphasized.

\section{Sample preparation and phase-structure characterization}

Magnesium-rich alloys with nominal compositions, Mg ${ }_{85} \mathrm{Ni}_{10} \mathrm{La} 5$ and $\mathrm{Mg}_{90} \mathrm{Ni}_{10}$ (in at.\%), have been prepared in this study. Appropriate amounts of raw materials $(99.9 \%$ pure $\mathrm{Mg}$ and $99.9 \%$ pure $\mathrm{La}$ ) and a mother alloy $\left(\mathrm{Mg}_{70} \mathrm{Ni}_{30}\right)$ are mixed together, melted at $900^{\circ} \mathrm{C}$ in sealed steel crucibles under high purity Ar atmosphere and slowly cooled. The chemical compositions of the ingots obtained by SEM-EDX analyses are $\mathrm{Mg}_{89.2 \mathrm{Ni} .6 \mathrm{La} 3.2}$ and Mg89.5Ni10.5. Amorphous ribbons ( $20 \mu \mathrm{m}$ thick and $\sim \mathrm{mm}$ wide) are prepared from these ingots with a melt-spinning technique using a single $\mathrm{Cu}$ roll under Ar atmosphere. They are cut into small pieces, slightly ground and subjected to H/D measurements using a Sievertstype PCT apparatus. The crystallization temperature $T_{x}$ for these amorphous alloys as determined by DSC measurements is $162 \pm 5^{\circ} \mathrm{C}$, which is well below the initial activation temperature $300^{\circ} \mathrm{C}$ adopted for hydrogenation in this study, hence all the $\mathrm{H} / \mathrm{D}$ measurements have been performed for the crystallized alloys.

The SEM photographs for the as-cast $\mathrm{Mg}_{90} \mathrm{Ni}_{10}$ and $\mathrm{Mg}_{85} \mathrm{Ni}_{10} \mathrm{La}$ a alloys shown in Fig. 1 indicate that a primary dendritic phase of $\mathrm{Mg}(\alpha)$ is coexistent with $\mathrm{Mg}(\alpha) / \mathrm{Mg}_{2} \mathrm{Ni}(\gamma)$ eutectic phases in the former, whereas a primary equiaxial phase of $\mathrm{Mg}_{2} \mathrm{Ni}(\gamma)$ is coexistent with both the $\mathrm{Mg} / \mathrm{Mg}_{2} \mathrm{Ni}$ eutectic phases and a $\mathrm{Mg}_{17} \mathrm{La}_{2}$ compound phase in the latter. These phase structures are consistent with the equilibrium phase diagrams of $\mathrm{Mg}-\mathrm{Ni}$ (Massalski, 
1986) and Mg-Ni-La (De Negri at al.., 2005) systems. Since the grains of all the constituent phases are so coarse that the initial activation and subsequent H/D processes of the as-cast alloys inevitably become sluggish. However, this difficulty is overcome substantially by refining the microstructure employing higher cooling rates of casting (Yamada et al., 2001; Yin et al., 2002). The melt-spinning technique combined with the crystallization treatment employed here is a quite efficient method for attaining the grain refining. An equal channel angular pressing (ECAP) treatment has also been applied for the grain refining in a $\mathrm{Mg}-\mathrm{Ni}$ $\mathrm{Mm}$ alloy (L $\phi$ ken et al., 2006), and a high hydrogen absorbency exceeding $5 \mathrm{wt} \% \mathrm{H}$ with moderate $\mathrm{H} / \mathrm{D}$ kinetics has been attained.

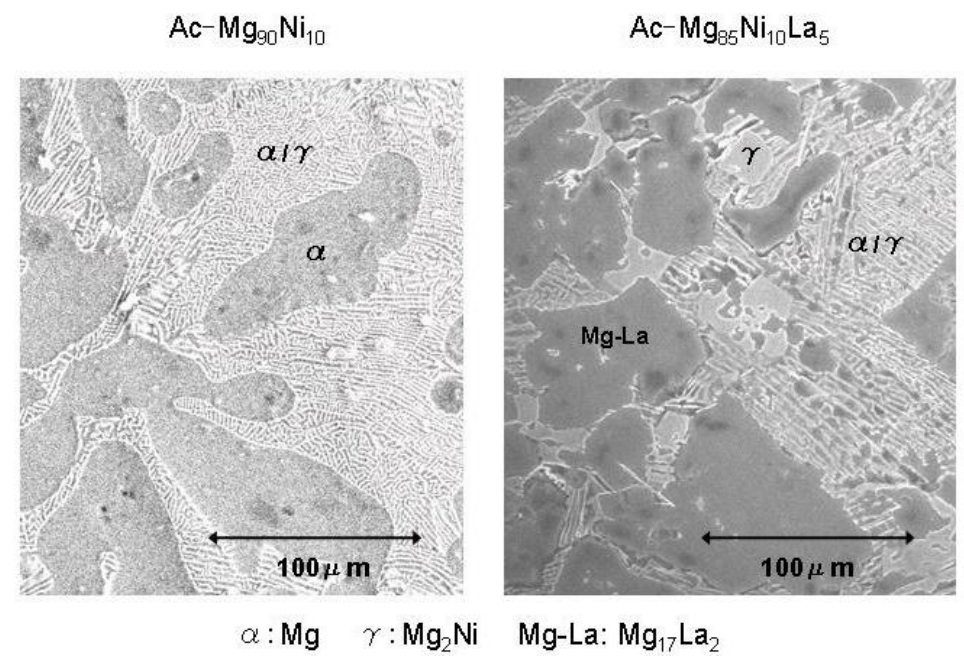

Figure 1. SEM photographs of as-cast $\mathrm{Mg}{ }_{90} \mathrm{Ni}_{10}$ and $\mathrm{Mg}{ }_{85} \mathrm{Ni}_{10} \mathrm{La}_{5}$ alloys.

The phase structures of melt-spun $\mathrm{Mg}_{90} \mathrm{Ni}_{10}$ and $\mathrm{Mg}{ }_{85} \mathrm{Ni}_{10} \mathrm{La}$ a alloys have been examined for the samples subjected to crystallization annealing, hydriding and dehydriding treatments at $300^{\circ} \mathrm{C}$ using X-ray diffraction with $\mathrm{Cu} \mathrm{K} \alpha$ radiation, as shown in Fig. 2. After crystallization, the $\mathrm{Mg}_{90} \mathrm{Ni}{ }_{10}$ alloy is composed of $\mathrm{Mg}+\mathrm{Mg}_{2} \mathrm{Ni}$ phases similarly to the as-cast alloy. After hydriding to $4.8 \mathrm{wt} \% \mathrm{H}, \beta-\mathrm{MgH}_{2}+\mathrm{Mg}_{2} \mathrm{NiH}_{4}$ phases appear, with a part of the $\mathrm{Mg}_{2} \mathrm{Ni}$ phase left unchanged. The $\mathrm{Mg}_{2} \mathrm{NiH}_{4}$ phase is separated to the low-temperature (LT) and hightemperature (HT) phases. The $\gamma-\mathrm{MgH}_{2}$ phase, which commonly exists in ball-milled $\mathrm{MgH}_{2}$ (Liang et al., 1999), is not formed in the melt-spun alloy. After dehydriding, the alloy recovers to the original $\mathrm{Mg}+\mathrm{Mg}_{2} \mathrm{Ni}$ phases. In the subsequent $\mathrm{H} / \mathrm{D}$ processes, the alloy phases cyclically change as:

$$
\mathrm{Mg}+\mathrm{Mg}_{2} \mathrm{Ni}+\mathrm{H}_{2} \leftrightarrow \mathrm{MgH}_{2}+\mathrm{Mg}_{2} \mathrm{NiH}_{4}\left(\mathrm{Mg}_{90} \mathrm{Ni} 10\right. \text { alloy) }
$$



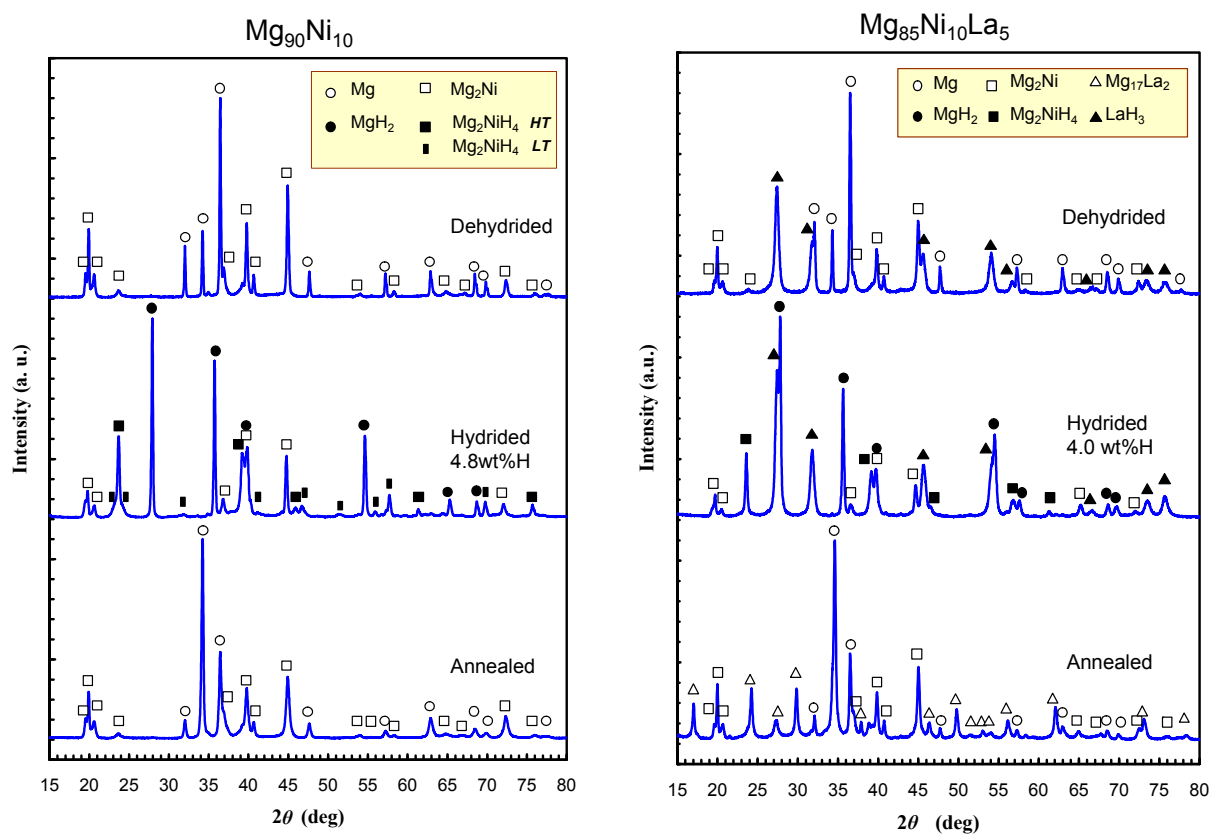

Figure 2. X-ray diffraction patterns $(\mathrm{Cu} \mathrm{K \alpha})$ of melt-spun $\mathrm{Mg}_{90} \mathrm{Ni}_{10}$ and $\mathrm{Mg}_{85} \mathrm{Ni}_{10} \mathrm{La} 5$ alloys subjected to crystallization annealing, hydriding and dehydriding at $300^{\circ} \mathrm{C}$.

On the other hand, the $\mathrm{Mg}_{85} \mathrm{Ni} 10 \mathrm{La} 5$ alloy is composed of $\mathrm{Mg}+\mathrm{Mg}_{2} \mathrm{Ni}+\mathrm{Mg}_{17} \mathrm{La} 2$ phases after crystallization similarly to the as-cast alloy. Upon hydriding to $4.0 \mathrm{wt} \% \mathrm{H}$, these metallic phases transform into $\beta-\mathrm{MgH}_{2}+\mathrm{Mg}_{2} \mathrm{NiH}_{4}(\mathrm{HT})+\mathrm{LaH}_{3}$ hydride phases. In this process, the $\mathrm{Mg}_{17 \mathrm{La}}$ phase is decomposed to $\mathrm{MgH}_{2}+\mathrm{LaH}_{3}$ through a disproportionation reaction. A part of the $\mathrm{Mg}_{2} \mathrm{Ni}$ phase is remaining. After dehydriding, $\mathrm{Mg}+\mathrm{Mg}_{2} \mathrm{Ni}$ metallic phases recover whereas the thermally stable $\mathrm{LaH}_{3}$ hydride remains unchanged. Thus, the $\mathrm{H} / \mathrm{D}$ processes for this alloy are simply written as:

$$
\begin{gathered}
\mathrm{Mg}+\mathrm{Mg}_{2} \mathrm{Ni}+\mathrm{Mg}_{17} \mathrm{La}_{2}+\mathrm{H}_{2} \rightarrow \mathrm{Mg}+\mathrm{Mg}_{2} \mathrm{Ni}+\mathrm{LaH}_{3}+\mathrm{H}_{2} \leftrightarrow \\
\mathrm{MgH}_{2}+\mathrm{Mg}_{2} \mathrm{NiH}_{4}+\mathrm{LaH}_{3}\left(\mathrm{Mg}_{5} \mathrm{Ni}_{10} \mathrm{La}_{5} \text { alloy }\right)
\end{gathered}
$$

The metallic and hydride phases described above provide stable nano-grain structures in these alloys, as shown later (Section 5 and 6).

\section{Pressure-composition isotherms and H/D kinetics}

Pressure $(p)$ - composition $(c)$ isotherms are measured for the crystallized and activated samples ( 1.0 g) with a volumetric method using a Sieverts-type apparatus. Figure 3 shows a result on $\mathrm{Mg}_{85} \mathrm{Ni}_{10} \mathrm{La} 5$ alloy for temperatures $(T)$ between $240^{\circ}$ and $330^{\circ} \mathrm{C}$, where the 
absorption and desorption isotherms are displayed with dashed and solid lines, respectively. Here, the $\mathrm{H}$-content $c$ is given by $c($ wt $\%)=($ weight of $\mathrm{H}) /($ weight of alloy + weight of $\mathrm{H}) \times 100$. All the isotherms clearly show two-stage plateaus. The first (lower pressure) stage corresponds to $\mathrm{Mg}-\mathrm{MgH}_{2}$, and the second (higher pressure) one to $\mathrm{Mg}_{2} \mathrm{Ni}-$ $\mathrm{Mg}_{2} \mathrm{NiH}_{4}$ equilibria. The H-capacity $(c \sim 4.6 \mathrm{wt} \%)$ and the ratio of the widths of the two stages, $\sim 3.8 / 0.8$, are consistent with those expected for the alloy assuming a complete hydride formation. It can be seen from the figure that the first stage is flat and exhibits only a small hysteresis except for the initial parts of the isotherms, whereas the second one is slightly inclined and exhibits a definite hysteresis which is more emphasized at lower temperatures.

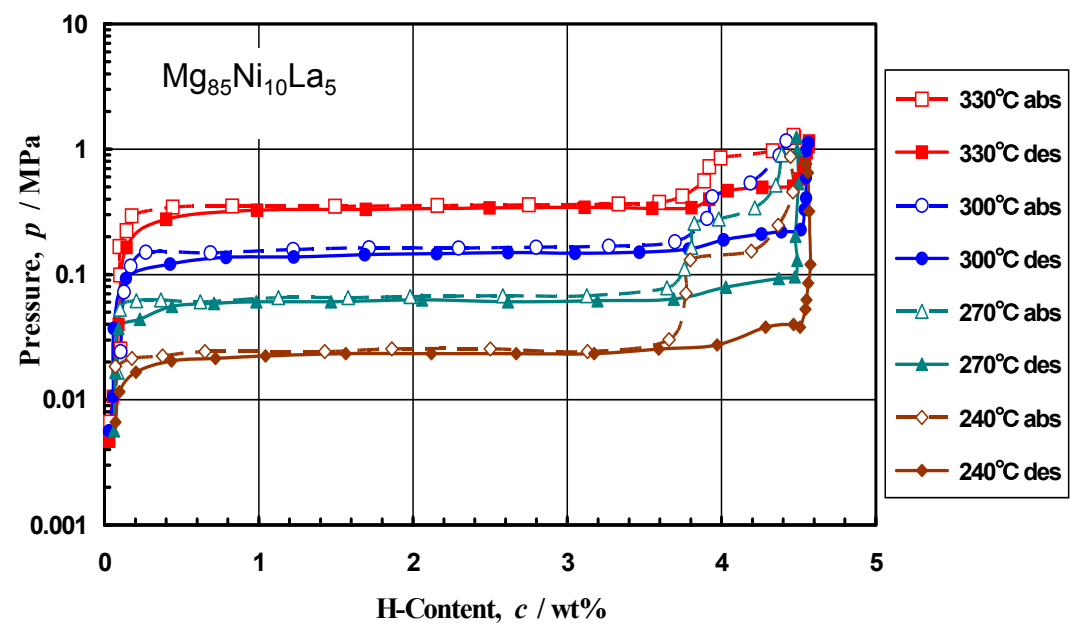

Figure 3. Pressure - composition isotherms for the melt-spun Mg85Ni10La5 alloy. (Tanaka, 2008)

Relationships between the pressure and inverse temperature for the first and second plateaus in the absorption and desorption processes are shown in Fig. 4. The formation enthalpy $\Delta H_{\mathrm{f}}$ and standard formation entropy $\Delta S_{\mathrm{f}}{ }^{0}$ for $\mathrm{MgH}_{2}$ and $\mathrm{Mg}_{2} \mathrm{NiH}_{4}$ are related with the plateau pressure $p$ and temperature $T$ as

$$
\ln \left(\frac{p}{p^{0}}\right)=\frac{\Delta H_{\mathrm{f}}}{R T}-\frac{\Delta S_{\mathrm{f}}^{0}}{R},
$$

where $p^{0}=0.1 \mathrm{MPa}$ and $R$ is the gas constant. They can be evaluated from the linear relationships shown in the figure. Values of $\Delta H_{\mathrm{f}}$ and $\Delta S_{\mathrm{f}}{ }^{0}$ are listed in Table 1 and compared with those for an ordinary coarse-grained material (Wiswall, 1978). The values for $\mathrm{MgH}_{2}$ are comparable between the melt-spun and ordinary alloys. However, those for $\mathrm{Mg}_{2} \mathrm{NiH}_{4}$ are definitely different between the two. Namely, the formation enthalpy and entropy for $\mathrm{Mg}_{2} \mathrm{NiH}_{4}$ are closer to those for $\mathrm{MgH}_{2}$ in the melt-spun alloy than in the ordinary alloys. 


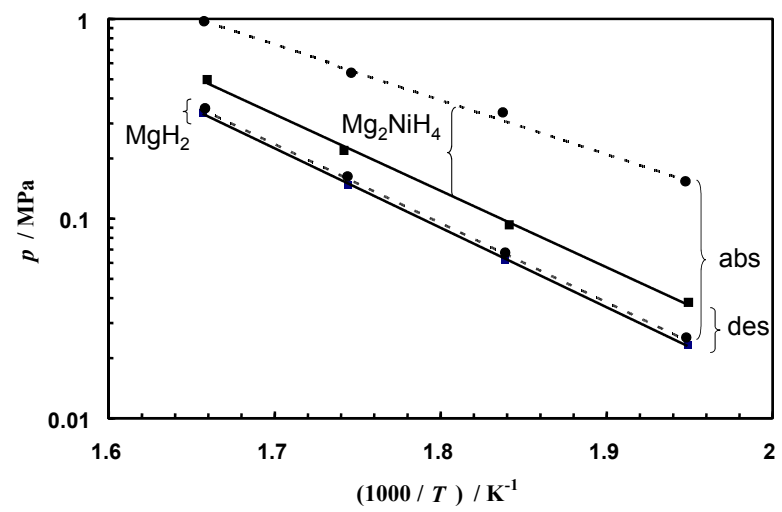

Figure 4. Relationships between plateau pressures $p$ and inverse temperatures $T^{-1}$ for hydrogen absorption (broken lines) and desorption (solid lines) in Mg${ }_{85} \mathrm{Ni10La}$ alloy. (Tanaka, 2008)

\begin{tabular}{cccc}
\hline Hydrides & Process & $\Delta H_{\mathrm{f}} /\left(\mathrm{kJ} / \mathrm{molH}_{2}\right)$ & $\Delta S_{\mathrm{f}^{0}} /\left(\mathrm{J} / \mathrm{K} / \mathrm{molH}_{2}\right)$ \\
\hline \multirow{2}{*}{$\mathrm{MgH}_{2}$} & abs & -75.9 & -136 \\
& des & $-76.2(-74.8)$ & $-136(-136)$ \\
$\mathrm{Mg}_{2} \mathrm{NiH}_{4}$ & abs & -52.0 & -105 \\
& des & $-73.3(-64.7)$ & $-135(-122)$ \\
\hline
\end{tabular}

Table 1. Thermodynamic parameters $\Delta H_{\mathrm{f}}$ and $\Delta S_{\mathrm{f}}^{0}$ for the formation of $\mathrm{MgH}_{2}$ and $\mathrm{Mg}_{2} \mathrm{NiH}_{4}$ in Mg85Ni10La5 alloy. The values in the parentheses are for an ordinary alloy.

Figure 5 shows PCT curves for the as-cast $\mathrm{Mg}_{85} \mathrm{Ni}_{10} \mathrm{La} 5$ alloy. Although the gross features of the isotherms are similar, the as-cast alloy provides more inclined plateaus than the meltspun alloy. Furthermore, the boundary between the first and second plateaus is less clearly defined in the former than the latter. These unfavorable features of the PCT characteristics of the as-cast alloy are possibly due to the presence of structural and compositional inhomogeneities such as coarse grains and $\mathrm{Mg} / \mathrm{Mg}_{2} \mathrm{Ni}$ eutectics. The PCT Measurements for the melt-spun $\mathrm{Mg}_{90} \mathrm{Ni} 10$ alloy have also been carried out, and isotherms qualitatively similar to those of melt-spun $\mathrm{Mg}_{85} \mathrm{Ni} 10 \mathrm{La} 5$ alloy (Fig. 3) have been obtained. However, the measured H-capacity $(c \sim 4.6 \mathrm{wt} \%)$ is substantially smaller than that expected for the alloy $(\sim 6.1 \mathrm{wt} \%)$. The isotherms show that the magnitude of the second plateau (formation of $\mathrm{Mg}_{2} \mathrm{NiH}_{4}$ ) is far smaller than that expected. A much slower reaction rate for the $\mathrm{Mg}_{2} \mathrm{NiH}_{4}$ formation in the $\mathrm{Mg}_{90} \mathrm{Ni}_{10}$ alloy than in the $\mathrm{Mg}_{85} \mathrm{Ni}_{10} \mathrm{La}$ 5 alloy might have caused this apparent loss of $\mathrm{H}$ capacity in the binary $\mathrm{Mg}_{90} \mathrm{Ni} 10$ alloy. 


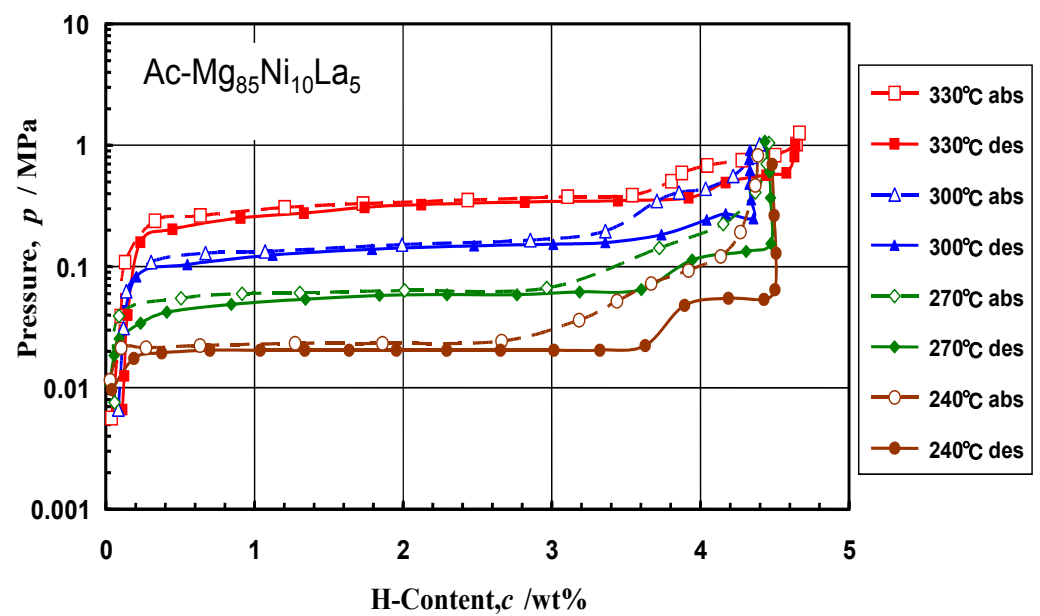

Figure 5. Pressure-composition isotherms for the as-cast Mg85Ni10La5 alloy. (Tanaka, 2008)

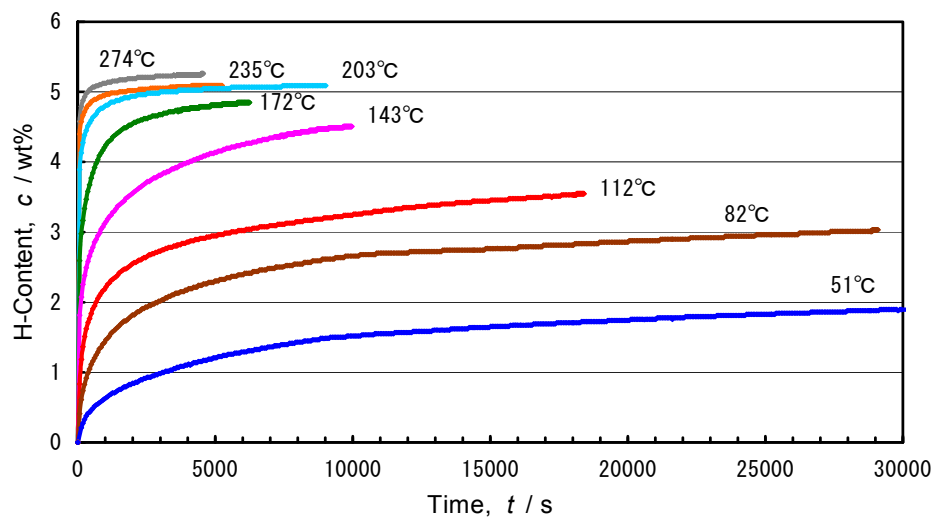

Figure 6. Hydrogen absorption characteristics of melt-spun Mg85Ni10La5 alloy. (Tanaka et al., 2009)

Figure 6 shows hydrogen absorption rates of a melt-spun $\mathrm{Mg}_{85} \mathrm{Ni}_{10} \mathrm{La}$ 5 alloy ( 150 mg) at temperatures between $51^{\circ}$ and $274^{\circ} \mathrm{C}$ under $\mathrm{H}_{2}$ pressures well above the corresponding plateau pressures of $\mathrm{Mg}_{2} \mathrm{NiH}_{4}$ and $\mathrm{MgH}_{2}$. In the measurements of $\mathrm{H} / \mathrm{D}$ kinetics, the $\mathrm{H}-$ content is defined, for convenience, as $c(w t \%)=($ weight of $\mathrm{H}) /($ weight of alloy $) \times 100$. At temperatures above $200^{\circ} \mathrm{C}$, a maximum $\mathrm{H}$-content of $c \sim 5 \mathrm{wt} \%$ is readily reached within $\sim 0.5$ $\mathrm{h}$, although the absorption rate is drastically reduced at lower temperatures. This behavior is qualitatively similar to those of ball-milled $\mathrm{MgH}_{2}$ added with transition metals (Liang et al., 1999) or transition metal-oxides (Hanada et al. 2006; Oelerich, 2001). These absorption curves reflect complex underlying processes depending on $T$ and $p$, for which simple analytical expressions are unavailable at present except for the initial parts of absorption (Hanada et al., 2007). 


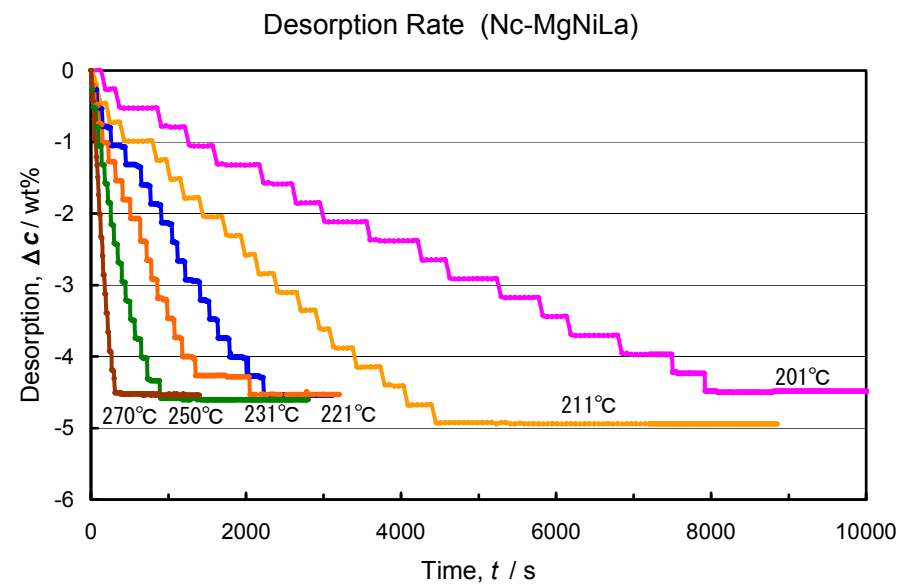

Figure 7. Hydrogen desorption characteristics of melt-spun Mg${ }_{85} \mathrm{Ni10La}$ alloy. (Tanaka et al., 2009)

Figure 7 shows hydrogen desorption rates of the same sample as above at temperatures between $201^{\circ}$ and $270^{\circ} \mathrm{C}$. For these measurements, the sample is initially saturated with hydrogen $(\sim 5 \mathrm{wt} \% \mathrm{H})$ by equilibrating with $\mathrm{H}_{2}$ gas above the plateau pressure of $\mathrm{Mg}_{2} \mathrm{NiH}_{4}$ at the measuring temperature. The chamber is then instantly evacuated to lower than 0.001 $\mathrm{MPa}$, well below the plateau pressure of $\mathrm{MgH}_{2}$, and the subsequent increment in pressure due to desorption from the sample is recorded. It can be seen from this figure that the absorbed hydrogen is almost wholly desorbed in a reasonable time period in the measured temperature range. The desorption appears to take place according to an equation

$$
c=c_{0}-r t
$$

where $c 0$ is the initial $\mathrm{H}$-content, $t$ the desorbing time and $r$ is a rate constant that depends on the temperature. Assuming that $r$ is given by an Arrhenius-type equation

$$
r=r_{0} \exp \left(-\frac{E_{\mathrm{d}}}{R T}\right),
$$

$E_{\mathrm{d}}$ (apparent activation energy for desorption) is calculated as $98.1 \mathrm{~kJ} / \mathrm{mol} \mathrm{H}_{2}$, as shown in Fig. 8. This value is definitely larger than the enthalpies of decomposition of $\mathrm{MgH}_{2}(76.2$ $\left.\mathrm{kJ} / \mathrm{mol} \mathrm{H}_{2}\right)$ and $\mathrm{Mg}_{2} \mathrm{NiH}_{4}\left(73.3 \mathrm{~kJ} / \mathrm{mol} \mathrm{H}_{2}\right)$. The linear time dependence given by eq. (2) may reflect a rate-controlling process at the powder surface of the alloy. Namely, hydrogen is desorbed from the surface at a constasnt rate irrespective of the $\mathrm{H}$-content. The activation energy $E_{\mathrm{d}}$ for this alloy is intermediate between those for undoped $\mathrm{MgH}_{2}\left(\sim 120 \mathrm{~kJ} / \mathrm{mol} \mathrm{H}_{2}\right)$ and for $\mathrm{Nb}_{2} \mathrm{O}_{5}$-doped $\mathrm{MgH}_{2}$ prepared by ball milling $\left(62 \mathrm{~kJ} / \mathrm{mol} \mathrm{H}_{2}\right)$ (Barkhordarian, 2004). The desorption process of hydrogen will be discussed in conjunction with TDS measurements later (Section 4). 


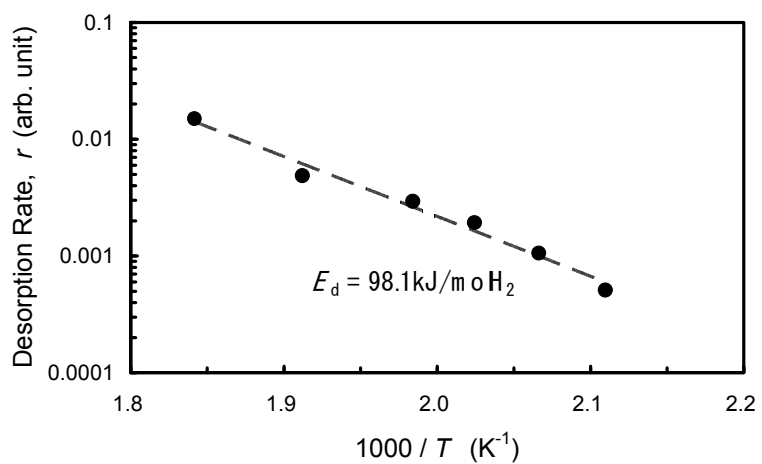

Figure 8. The desorption rate $r$ for melt-spun $\mathrm{Mg}_{85} \mathrm{Ni}_{10} \mathrm{La} 5$ plotted against $T^{-1}$. (Tanaka et al., 2009)

\section{Thermal desorption spectroscopy for hydrogen}

The thermal desorption spectroscopy (TDS) is a technique in which a small piece of hydrogenated sample is heated at a constant rate in high vacuum, and the H-desorption rate is measured by monitoring the partial gas pressure of hydrogen as a function of temperature. In the present experiment, a powder specimen $(\sim 10 \mathrm{mg})$ is measured at a heating rate between $0.5^{\circ}$ and $4^{\circ} \mathrm{C} / \mathrm{min}$ in a vacuum of $\sim 10^{-6} \mathrm{~Pa}$ using an apparatus equipped with a turbo-molecular pumping system and a quadrupole mass spectrometer, as shown in Fig. 9. A sample cell compatible with the PCT measurement is used. With this cell, a hydrogenated sample is transferred from the PCT to TDS apparatus for measuring a desorption spectrum, or vice versa for loading the specimen with hydrogen, without exposing to the air. This process is repeated several times for a single specimen in a series of measurements to examine the heating-rate dependence of a TDS spectrum or to examine the effect of thermal cycles on the spectrum.

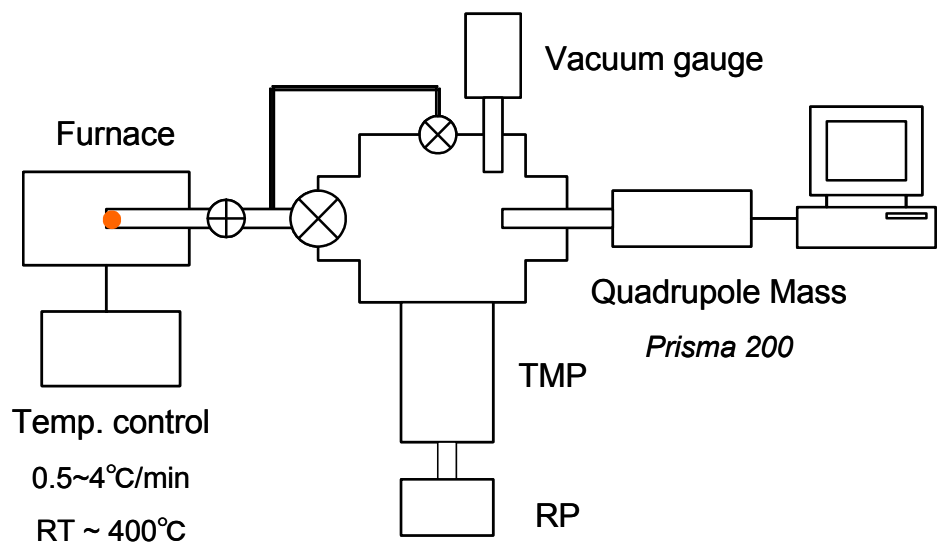

Figure 9. Apparatus used for TDS measurements. 


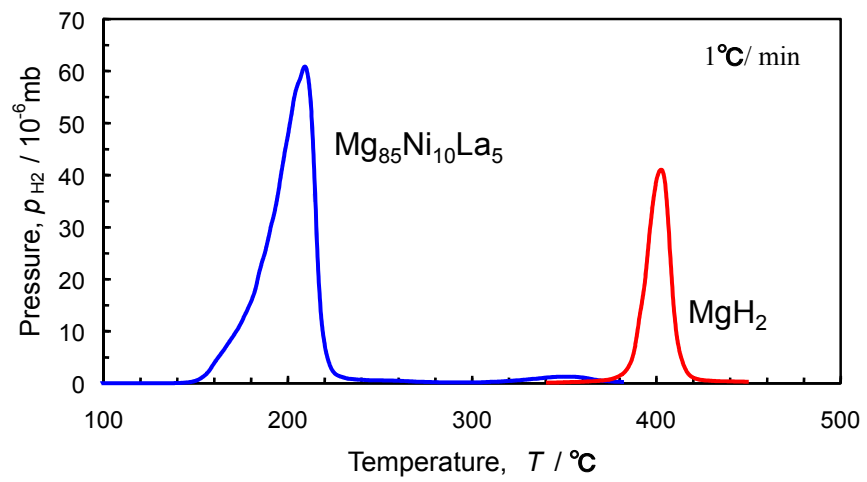

Figure 10. TDS spectrum of a hydrogenated melt-spun Mg85 Ni10La5 alloy compared with that of commercial $\mathrm{MgH}_{2}$ powder.

Figure 10 shows an example of TDS spectrum of a hydrogenated $\mathrm{Mg}_{85} \mathrm{Ni}_{10} \mathrm{La}_{5}$ alloy stabilized by exposing to a few hydrogenation/thermal desorption cycles at $300^{\circ} \mathrm{C}$, compared with that of commercial $\mathrm{MgH}_{2}$ powder. In this figure, a hydrogen partial pressure derived from a measured ion current of the mass spectrometer is plotted against a specimen temperature. The partial pressure can be used as a measure of hydrogen desorption rate if the pumping speed of the apparatus is assumed to be constant irrespective of the pressure. Clearly, a prominent peak with a few substructures occurs around $200^{\circ} \mathrm{C}$ in the $\mathrm{Mg}_{85} \mathrm{Ni}_{10} \mathrm{La} 5$ alloy, while a single peak is caused around $400^{\circ} \mathrm{C}$ in $\mathrm{MgH}_{2}$, indicating that the desorption temperature is significantly reduced in the melt-spun alloy. Although the nature of the TDS spectrum of the alloy is not clear solely from this figure, it will be shown in the following that the main peak as well as the substructures is related with thermal decomposition of hydride phases present in the alloy.

Figure 11 shows TDS spectra, measured at $1^{\circ} \mathrm{C} / \mathrm{min}$ (left) and $2^{\circ} \mathrm{C} / \mathrm{min}$ (right), of meltspun $\mathrm{Mg}_{85} \mathrm{Ni}_{10} \mathrm{La} 5$ alloy subjected to hydrogenation/thermal desorption cycles ( $1^{\text {st }}$ to $4^{\text {th }}$ ). Prior to each desorption measurement, the sample has been fully hydrogenated at $\sim 300^{\circ} \mathrm{C}$ under $\sim 1 \mathrm{MPaH}_{2}$. Each spectrum is optionally shifted vertically for the sake of clarity. Except for apparent upward shifts of peak temperatures for the higher heating rate, the two sets of spectra provide common features with increasing cycles. In the $1^{\text {st }}$ cycle, a broad peak $c$ is dominantly seen together with a shoulder associated with peak $b$. In the $2^{\text {nd }}$ cycle, peak $b$ develops while peak $c$ diminishes without altering the total peak area appreciably. In the $3^{\text {rd }}$ and $4^{\text {th }}$ cycles, peak $b$ further develops and becomes narrower while peak $c$ changes less. Throughout these processes, peak $d$ changes little. Beyond the $4^{\text {th }}$ cycle, the spectral change almost ceases and all the peaks remain stable if the measuring temperature is not increased beyond $\sim 400^{\circ} \mathrm{C}$. A substructure, $a$, is occasionally observable as a shoulder on the lower-temperature tail of peak $b$, but it is not always reproducible in these measurements. 

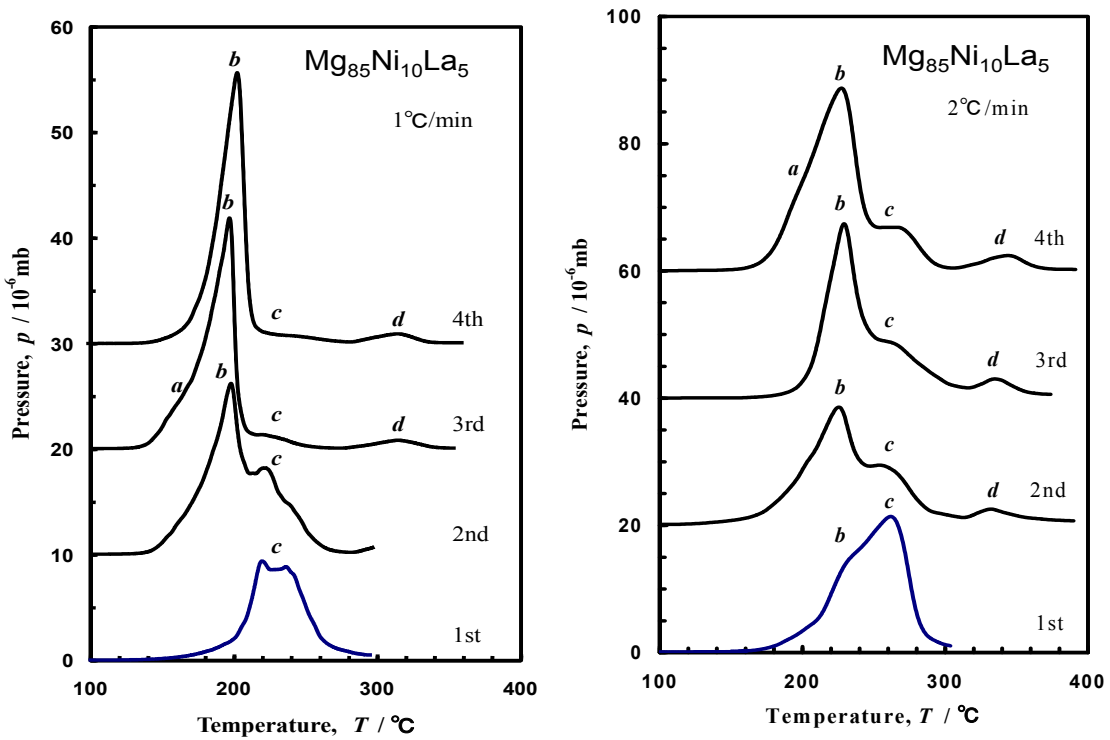

Figure 11. Evolution of TDS peaks of melt-spun $\mathrm{Mg}{ }_{85} \mathrm{Ni}_{10} \mathrm{La}$ alloys subjected to $1^{\text {st }}$ to $4^{\text {th }}$ hydrogenation/thermal desorption cycles measured with heating rates of $1{ }^{\circ} \mathrm{C} / \mathrm{min}$ (left) and $2^{\circ} \mathrm{C} / \mathrm{min}$ (right). (Tanaka, 2008)

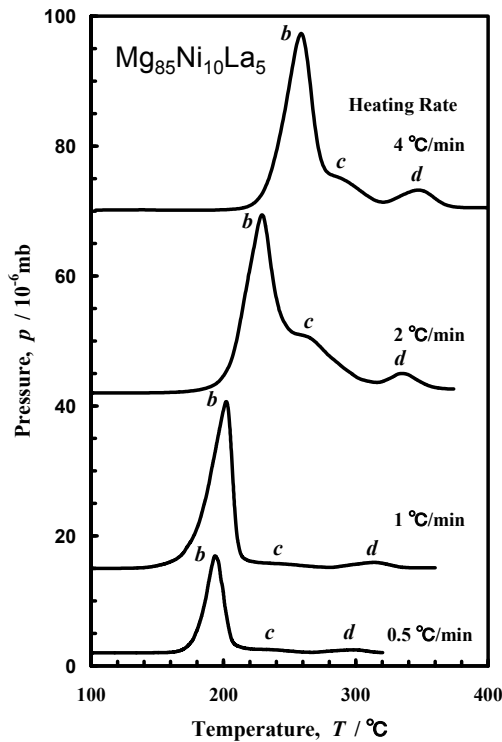

Figure 12. Heating-rate dependence of the TDS profiles of Mg85 ${ }_{85} \mathrm{Ni}_{10 \mathrm{La}}$ subjected to $4^{\text {th }}$ hydrogenation/desorption cycle. (Tanaka, 2008) 
In Fig. 12, TDS spectra of Mg85Ni10La5 measured at different heating rates $(0.5,1,2$, and $4^{\circ} \mathrm{C} / \mathrm{min}$ ) are compared, where a spectrum stabilized by subjecting at least four hydrogenation/thermal desorption cycles is chosen as a representative for each heating rate. It can be seen from the figure that, with increasing heating rate, peaks $b$ to $d$ systematically shift toward higher temperatures, although peak $a$ is not well defined in these spectra. Furthermore, the integrated strength of each peak tends to increase with increasing heating rate. The latter feature is a natural effect of the TDS technique. The observed peak shifts are analyzed according to Kissinger's method below.

The relation between the heating rate $\beta$ and peak temperature $T_{\mathrm{m}}$ is shown in Fig. 13, where $\beta / \mathrm{Tm}^{2}$ is plotted against $T_{\mathrm{m}}{ }^{-1}$ in a semi-log scale for the peaks $b$ to $d$. Nearly linear relations can be seen, indicating that Kissinger's equation,

$$
\ln \left(\beta / T_{\mathrm{m}}^{2}\right)=-E_{\mathrm{des}} / R T_{\mathrm{m}}+\ln k_{0}
$$

holds for these peaks. Here, $E_{\text {des }}$ denotes an apparent activation energy for desorption and $k_{0}$ is a reaction constant. Values of $E_{\text {des }}$ obtained in this way are also given in the figure.

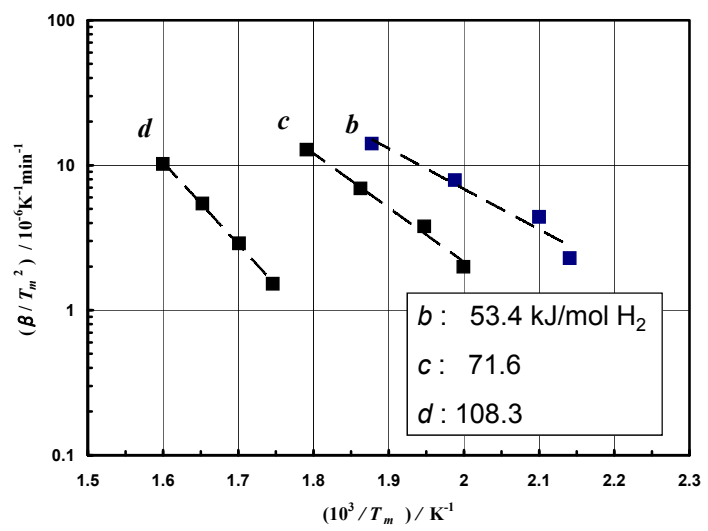

Figure 13. Kissinger's plots for the TDS peaks $b \sim d$ of Fig.12. Values of $E_{\text {des }}$ are given. (Tanaka, 2008)

To examine further the evolution of TDS spectra due to heating up to higher temperatures $\left(\sim 380^{\circ} \mathrm{C}\right)$, measurements have been done for a single specimen of melt-spun $\mathrm{Mg}{ }_{85} \mathrm{Ni}_{10 \mathrm{La}}$ alloy using $\mathrm{D}_{2}$ gas, instead of $\mathrm{H}_{2}$ gas, as shown in Fig. 14. The specimen is fully pre-charged at $300^{\circ} \mathrm{C}$ under $1 \mathrm{MPa}$ of $\mathrm{D}_{2}$ pressure in every cyclic measurement, and heated from room temperature up to $300^{\circ} \mathrm{C}$ for the $1^{\text {st }}$ to $5^{\text {th }}$ cycles, and up to $\sim 380^{\circ} \mathrm{C}$ for the $6^{\text {th }}$ to $10^{\text {th }}$ cycles at a rate of $1^{\circ} \mathrm{C} / \mathrm{min}$. The spectral feature and its variation up to the $6^{\text {th }}$ cycle are similar to those shown in Fig. 11. A sharp prominent peak $b$ at $\sim 210^{\circ} \mathrm{C}$ is stabilized if the specimen temperature is kept below $300^{\circ} \mathrm{C}$. However, if the temperature is raised to $\sim 380^{\circ} \mathrm{C}$ in the $7^{\text {th }}$ to $10^{\text {th }}$ cycles, a drastic change takes place; the main peak $b$ undergoes significant broadening and shifts toward higher temperatures, causing a single peak at $\sim 280^{\circ} \mathrm{C}$ in the $10^{\text {th }}$ cycle. In this cycle, both the amount of pre-charged hydrogen and its absorption rate are markedly 
reduced. This result shows that the internal structure of the specimen is altered to some extent by heating up to $\sim 380^{\circ} \mathrm{C}$ repeatedly.

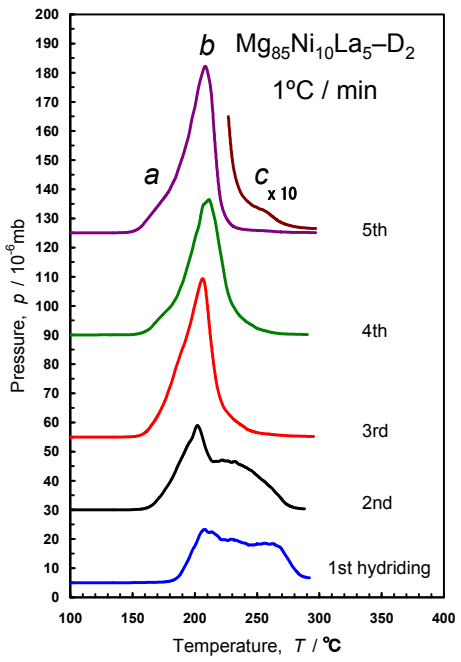

(a)

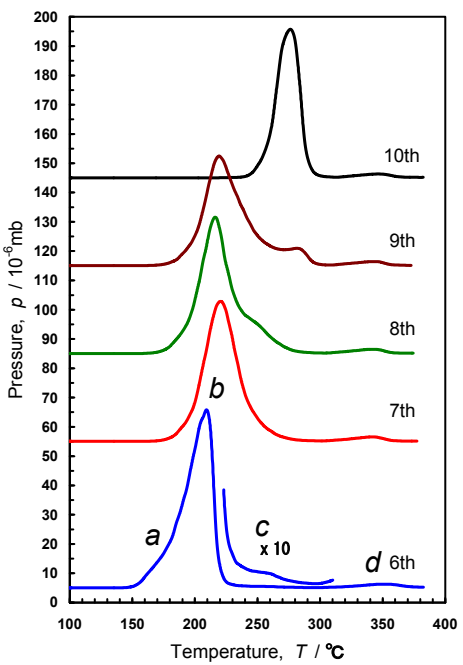

(b)

Figure 14. Evolution of TDS spectra of melt-spun Mg85Ni10La5- $\mathrm{D}_{2}$ system from $1^{\text {st }}$ to $5^{\text {th }}$ cycles (a) and from $6^{\text {th }}$ to $10^{\text {th }}$ cycles (b). (Tanaka et al., 2009)

Figure 15 shows TDS spectra, measured at $1^{\circ} \mathrm{C} / \mathrm{min}$, of a melt-spun $\mathrm{Mg}{ }_{90} \mathrm{Ni} 10$ alloy subjected to the hydrogenation/thermal desorption cycle as mentioned above. We find that, in contrast to $\mathrm{Mg}_{85} \mathrm{Ni}_{10} \mathrm{La}$ 5, peak $d$ is absent in $\mathrm{Mg}_{80} \mathrm{Ni}_{10}$, indicating that this peak is exclusively derived from $\mathrm{LaH}_{3}$ hydride present only in the $\mathrm{Mg}_{85} \mathrm{Ni}_{10 \mathrm{La}}$ alloy. We also find that peak $b$ and peak $c$ really exist in the $1^{\text {st }}$ cycle, but peak $c$ is much smaller than peak $b$ even in the $1^{\text {st }}$ cycle. The peak $c$ quickly decays with increasing number of cycle, leaving only the peak $b$ beyond the $4^{\text {th }}$ cycle. These spectral features of $\mathrm{Mg}_{90} \mathrm{Ni}_{10}$ are somewhat different from those of $\mathrm{Mg}_{85} \mathrm{Ni}_{10} \mathrm{La} 5$ shown in Fig. 11. This difference of TDS spectra is possibly associated with the difference in the thermal stability of the structures formed in these alloys. The behavior of peak $b$ of $\mathrm{Mg}_{90} \mathrm{Ni} 10$ at different heating rates has also been examined and a result analogous to that of $\mathrm{Mg}_{85} \mathrm{Ni}_{10 \mathrm{La}}$ (Fig. 12) has been obtained.

In the following, we discuss the origins of TDS peaks $a \sim d$ of melt-spun $\mathrm{Mg}_{85} \mathrm{Ni}_{10 \mathrm{La}}$ alloy and their behavior with the thermal cycles. It seems to be reasonable to assume that when a hydrogenated sample is slowly heated in vacuum, the thermal desorption, or the decomposition of hydrides, takes place according to a reaction process as manifested by the PCT desorption isotherms of the sample. Referring to Fig. 3, the main peak $b$ at $\sim 200^{\circ} \mathrm{C}$ and its lower-temperature shoulder $a$ in Figs. 11 and 14 are attributable to the decompositions of $\mathrm{MgH}_{2}$ and $\mathrm{Mg}_{2} \mathrm{NiH}_{4}$, respectively. The plateau pressure for the decomposition of $\mathrm{Mg}_{2} \mathrm{NiH}_{4}$ becomes closer to that of $\mathrm{MgH}_{2}$ as the temperature decreases. This might be a reason why 
the shoulder $a$ is not clearly defined as a single peak in the TDS spectra. Now, peak $c$ at $\sim 250^{\circ} \mathrm{C}$, which is broad but well defined in the $1^{\text {st }}$ cycle, progressively shrinks with increase in the number of cycle; peak $b$ develops at the expense of peak $c$ instead. This peak might be attributable to desorption of hydrogen dissolved in unstable grain boundaries (nanoboundaries) existing in high density after the crystallization. Most of these boundary regions are expected to transform to nano-crystalline $\mathrm{Mg}$ grains to form $\mathrm{MgH}_{2}$ in the following $2^{\text {nd }}$ to $6^{\text {th }}$ cycles. The fact that the main peak $b$ is broadened and shifts toward higher temperatures when the alloy is heated up to $\sim 380^{\circ} \mathrm{C}$ ( $7^{\text {th }}$ to $10^{\text {th }}$ cycles) suggests that the nanostructure is altered to some extent allowing redistribution and coarsening of the nano-grains. In this temperature range, the stable $\mathrm{LaH}_{3}$ hydrides are also decomposed to form coarse grains of metallic La, resulting in destabilizing the nano-grain structure of the alloy. This structural change will necessarily lead to retarding the decomposition reaction of hydrides and the subsequent hydrogen transport toward the alloy surfaces. Indeed, a much longer time is required for hydrogenating the sample at $300^{\circ} \mathrm{C}$ in the $10^{\text {th }}$ cycle in comparison with those in the $2^{\text {nd }}$ to $6^{\text {th }}$ ones. The structural change suggested above has been really confirmed by TEM observation, as shown later (Section 5 and 6).

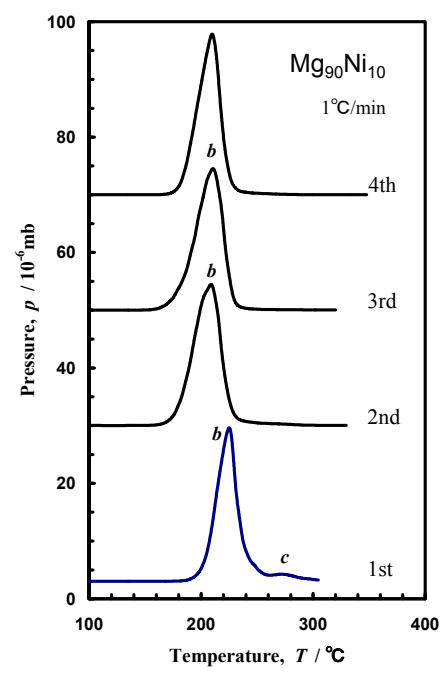

Figure 15. Evolution of TDS peaks of a melt-spun Mg $9_{00} \mathrm{Ni1} 10$ alloy subjected to $1^{\text {st }}$ to $4^{\text {th }}$ hydrogenation/thermal desorption cycles. (Tanaka, 2008)

We next discuss the hydrogen desorption process in melt-spun $\mathrm{Mg}_{85} \mathrm{Ni}_{10 \mathrm{La}}$ alloy. As mentioned in connection with eq. (2), the linear time dependence of $\mathrm{H}$-desorption at a fixed temperature suggests that the surface reaction is a rate-controlling step for the process. Namely, the decomposition of hydrides and subsequent diffusion of hydrogen toward external surfaces of powder grains occur quickly enough to establish a homogeneous hydrogen distribution within the grains. Thus, hydrogen in a grain may be assumed to be in a quasi-equilibrium state during the desorption. Although data for $\mathrm{H}$-diffusion in $\mathrm{Mg}$-rich 
nano-crystalline alloys are unavailable at present, the H-diffusivity along grain boundaries may be higher than those in $\mathrm{Mg}$ and $\mathrm{Mg}_{2} \mathrm{Ni}$ grains, or in $\mathrm{MgH}_{2}$ and $\mathrm{Mg}_{2} \mathrm{NiH}_{4}$ hydrides (Spassov \& Köster, 1999). Hydrogen atoms released from the hydrides inside a grain (diameter $<\sim 5 \mu \mathrm{m}$ ) might quickly diffuse through nano-boundaries toward the surface of the grain and be chemisorbed on some surface sites such as $\mathrm{Mg}_{2} \mathrm{Ni}$ nano-grains (Yamaga et al., 2008). Hydrogen molecules are desorbed from the chemisorbed sites into vacuum via a recombination reaction.

Now, we consider a thermal desorption spectrum for a simple isolated system of hydrogen atoms adsorbed on an $\mathrm{Mg}_{2} \mathrm{Ni}$ grain surface. The peak temperature of the TDS spectrum is just given by eq. (4) with $E_{\text {des }}=E_{\text {ad, }}$ adsorption energy of a hydrogen molecule. In a real system, where hydrogen is continuously supplied from an interior hydride to the surface sites, a modified relation, $E_{\text {des }}=E_{\text {ad }}+E_{\text {bind, }}$ may hold, where $E_{\text {bind }}$ is an effective binding energy of hydrogen of the hydride relative to the surface sites. The effective binding energy may be evaluated from the formation enthalpy $\Delta H_{\mathrm{f}}$ of the hydride, as shown below.

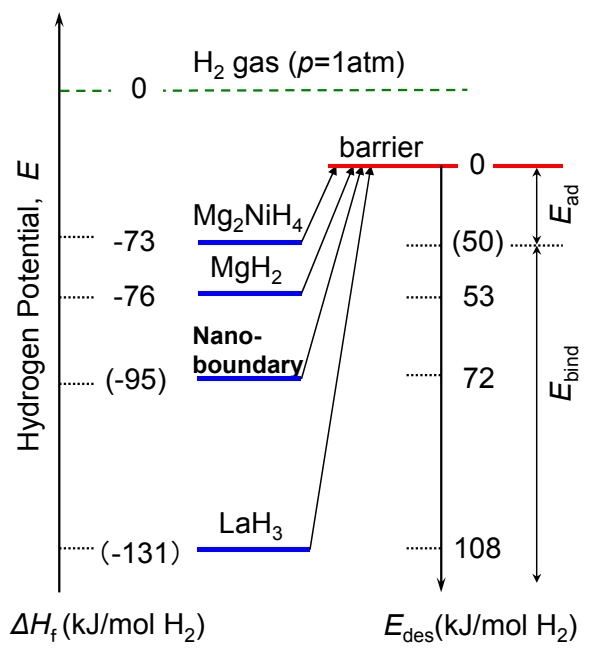

Figure 16. Hydrogen potential energy diagram in melt-spun $\mathrm{Mg}_{85} \mathrm{Ni}_{10} \mathrm{La}{ }_{5}$ alloy, showing interrelations between the formation enthalpies of hydrides, $\Delta H_{\mathrm{f}}$, and the activation energy of desorption, $E_{\text {des. }}$

(Tanaka, 2008)

Figure 15 displays a potential energy diagram of hydrogen existing in the hydrides or nanoboundaries in melt-spun $\mathrm{Mg}_{85} \mathrm{Ni}_{10} \mathrm{La} 5$ relative to that of the gas phase at standard state. Here, the formation enthalpy $\Delta H_{\mathrm{f}}$ is taken as the potential energy $E$ in a hydride, and values given in Table 1 (desorption process) are used for the $\mathrm{MgH}_{2}$ and $\mathrm{Mg}_{2} \mathrm{NiH}_{4}$ hydrides. The potential energies for hydrogen in the nano-boundaries and $\mathrm{LaH}_{3}$ are estimated and given in the parentheses. Now, we set an energy barrier of $E_{\mathrm{ad}}=50 \mathrm{~kJ} / \mathrm{mol} \mathrm{H} 2$ above the potential of 
$\mathrm{Mg}_{2} \mathrm{NiH}_{4}$ hydride for the desorption of hydrogen. (In the real system, desorption from $\mathrm{Mg}_{2} \mathrm{Ni}$ grain surface will occur, for which an alternate value of $E_{\text {ad }}$ must be used. In the present model, direct desorption from $\mathrm{Mg}_{2} \mathrm{NiH}_{4}$ hydride surface is tentatively assumed.) Then the net activation energy for desorption is given by $E_{\text {des }}=E_{\text {ad }}+E_{\text {bind, }}$, where $E_{\text {bind }}$ means the potential depth referred to the $\mathrm{Mg}_{2} \mathrm{NiH}_{4}$ hydride. This value can be obtained from $E$ des measured by TDS (Fig. 13), as shown in the figure. In this way, $\Delta H_{\mathrm{f}}$ of nano-crystalline $\mathrm{LaH}_{3}$ is estimated at $-131 \mathrm{~kJ} / \mathrm{mol} \mathrm{H}$, for which a value of $-188 \mathrm{~kJ} / \mathrm{mol} \mathrm{H}_{2}$ is given in conventional material (Fukai, 1993). Furthermore, the potential energy of hydrogen dissolved in nano-boundaries (mean value) is estimated at $-95 \mathrm{~kJ} / \mathrm{mol} \mathrm{H}$, indicating that hydrogen in the nano-boundary is more stable than in $\mathrm{MgH}_{2}$ hydride by about $20 \mathrm{~kJ} / \mathrm{mol}$ $\mathrm{H}_{2}$. It should be argued here that the apparent energy for desorption, $E_{\mathrm{d}}=98.1 \mathrm{~kJ} / \mathrm{mol}$ $\mathrm{H}_{2}$, obtained by analyzing the desorption rates, $r$, at fixed temperatures for melt-spun $\mathrm{Mg}_{85} \mathrm{Ni}_{10} \mathrm{La}_{5}$ (eq. (3) and Fig. 8) is much larger than $E_{\text {des }}=53.1 \mathrm{~kJ} / \mathrm{mol} \mathrm{H}$ obtained from TDS for the decomposition of $\mathrm{MgH}_{2}$ in the same alloy. Reasons to explain this difference may not be simple. A big difference in the experimental conditions between the two measurements is that, while the TDS is always measured in a high vacuum of $10^{-6}$ to $10^{-5} \mathrm{~Pa}$, the measurement of the desorption-rate is performed under $p_{\mathrm{H} 2} \sim 10^{3} \mathrm{~Pa}$. In the latter case, a driving force correction is needed because the plateau pressure for the decomposition of the hydride becomes closer to $p_{\mathrm{H} 2}$ especially at lower temperatures (Fernandez \& Sanchez, 2002). This correction, however, has not been performed in the present study. Therefore, the present $E_{\mathrm{d}}$ value is expected to be lowered toward that of $E_{\text {des }}$ if the correction is correctly applied.

\section{High-resolution TEM and EELS studies of nanostructures}

Nano-sized structures of melt-spun $\mathrm{Mg}_{90} \mathrm{Ni}_{10}$ and $\mathrm{Mg}_{85} \mathrm{Ni}_{10} \mathrm{La}_{5}$ alloy subjected to crystallization, hydrogenation and dehydrogenation have been investigated using a Hitachi H-9000 electron microscope operated at $300 \mathrm{kV}$. High-resolution TEM (HRTEM) and electron energy-loss spectroscopy (EELS) imaging techniques have been employed to reveal the structures in detail. Each sample has been ground in acetone into a fine powder with a diameter of $\sim 1$ to $\sim 2 \mu \mathrm{m}$, dispersed on a carbon micro-grid, and inserted into the TEM sample chamber for observation. In the following, some results mainly on the $\mathrm{Mg}{ }_{85} \mathrm{Ni}_{10 \mathrm{La}}$ alloy are presented.

Figure 17 shows a TEM bright-field (BF) image and its electron diffraction (ED) pattern of melt-spun and crystallized $\mathrm{Mg}_{85} \mathrm{Ni}_{10} \mathrm{La}_{5}$ alloy. The ED pattern exhibits broad diffraction rings of $\mathrm{Mg}, \mathrm{Mg}_{2} \mathrm{Ni}$ and $\mathrm{Mg}_{17} \mathrm{La}_{2}$ phases, consistently with the XRD pattern of the same alloy shown in Fig. 2. The alloy is composed of homogeneous distribution of nano-sized grains of these phases. Figure 18 shows a HRTEM image of the encircled region of Fig. 17. Lattice fringes of $\mathrm{Mg}, \mathrm{Mg}_{2} \mathrm{Ni}$ and $\mathrm{Mg}_{17} \mathrm{La}$ 2 nano-grains are evidently seen. Their sizes range between 5 and $10 \mathrm{~nm}$. The outer regions of these grains are also composed of nano-grains of the same phases, although their lattice fringes are not observable in this figure. No evidence of the formation of $\mathrm{Mg} / \mathrm{Mg}_{2} \mathrm{Ni}$ eutectics has been found in the crystallized alloy. 


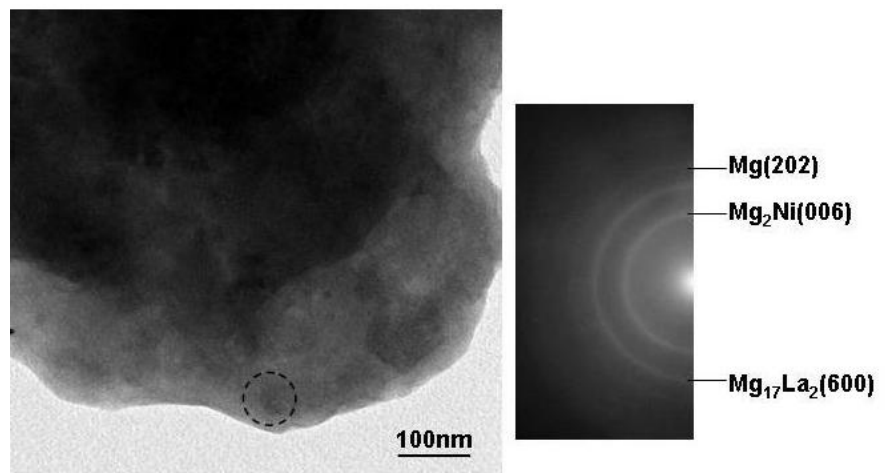

Figure 17. TEM bright-field image and its electron diffraction pattern of melt-spun and crystallized $\mathrm{Mg}_{85} \mathrm{Ni} 10 \mathrm{La} 5$ alloy.

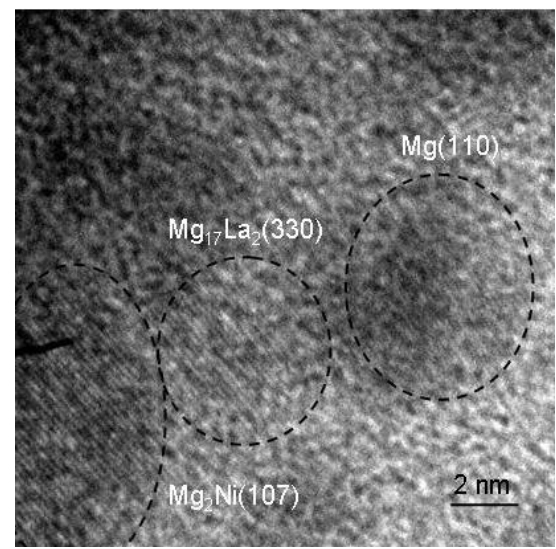

Figure 18. HRTEM image of the encircled region of the BF image shown in Fig. 17.

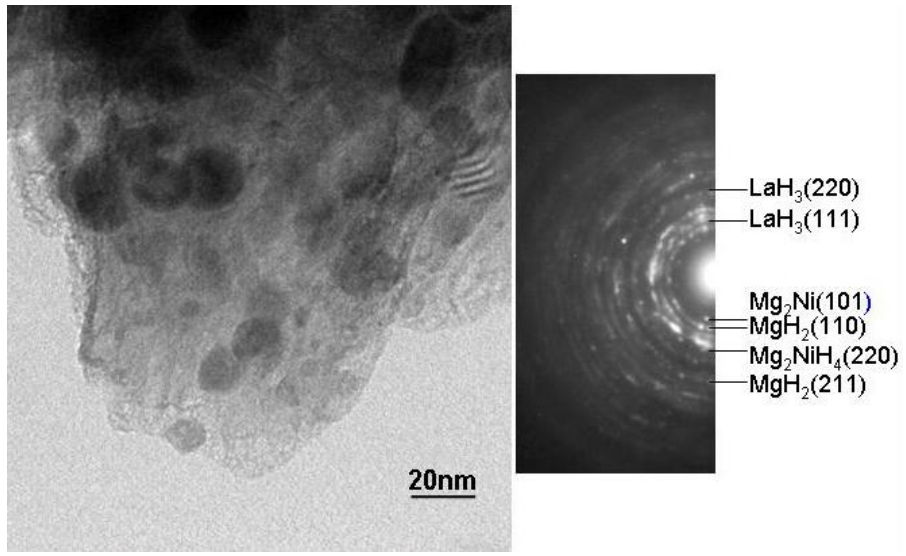

Figure 19. BF image of hydrogenated $\mathrm{Mg}_{85} \mathrm{Ni}_{10} \mathrm{La}_{5}$ alloy and its ED pattern. 
Fig. 19 shows a BF image and its ED pattern of hydrogenated $\mathrm{Mg}_{85} \mathrm{Ni}_{10} \mathrm{La} 5$ alloy. The ED pattern shows that $\mathrm{MgH}_{2}, \mathrm{Mg}_{2} \mathrm{NiH}_{4}$ and $\mathrm{LaH}_{3}$ hydrides are present together with remained $\mathrm{Mg}_{2} \mathrm{Ni}$ phase, in agreement with the XRD result shown in Fig. 2. The diffraction rings are not continuous but spotty, indicating that some grains of the hydride phases have undergone grain growth during the hydrogenation at $300^{\circ} \mathrm{C}$. In the $\mathrm{BF}$ image are seen spherical particles with dark-grey contrast dispersed in a matrix of light-grey contrast. The former are identified as nano-grains of $\mathrm{Mg}_{2} \mathrm{NiH}_{4}$ and $\mathrm{LaH}_{3}$ or their clusters and the latter as aggregates of $\mathrm{MgH}_{2}$ nano-grains by EELS and HRTEM micrographs shown below.

Figure 20 shows EELS mapping (Egerton, 1996) for the same sample area as in Fig. 19, where a plasmon loss $(\sim 10 \mathrm{eV}), \mathrm{Mg}-\mathrm{K}(1305 \mathrm{eV}), \mathrm{Ni}-\mathrm{L} 2,3(872,855 \mathrm{eV})$ and La-M4,5 $(849,832 \mathrm{eV})$ absorption edges are employed. The plasmon-loss image, denoted as H-plasmon here, represents the distribution of $\mathrm{MgH}_{2}$ phase (bright region) present in the sample, as explained in detail later (Section 6).
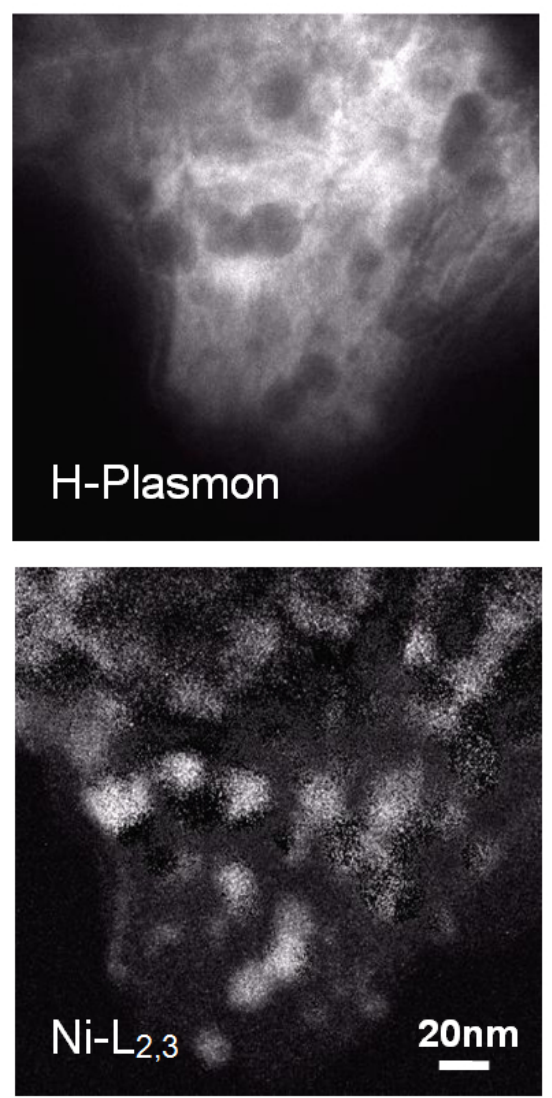
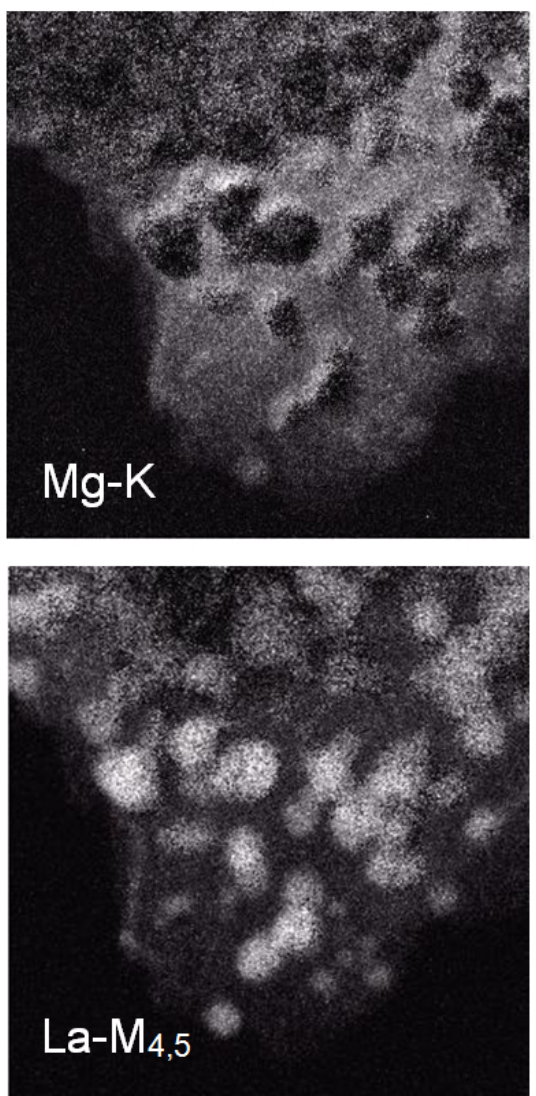

Figure 20. EELS mapping for the sample shown in Fig. 19, using H-plasmon, Mg-K, Ni-L2,3 and La-M4,5 absorption edges. 

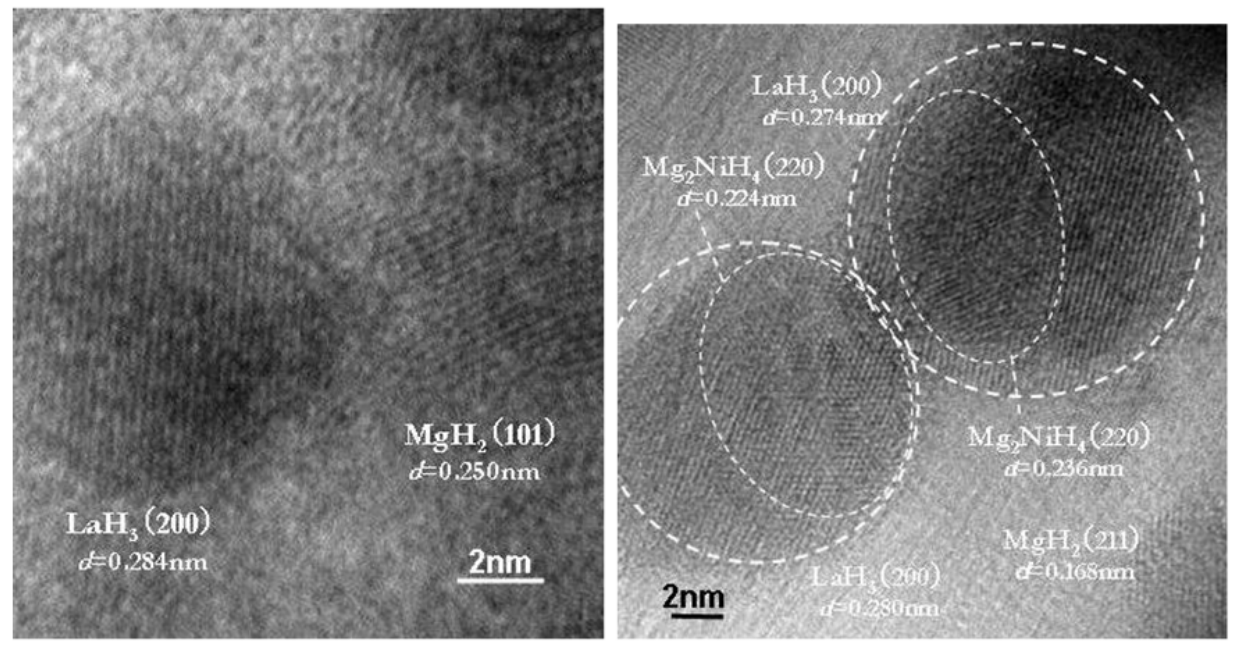

Figure 21. HRTEM images of areas at the lower part of the sample shown in Fig. 19. (Tanaka et al., 2009)

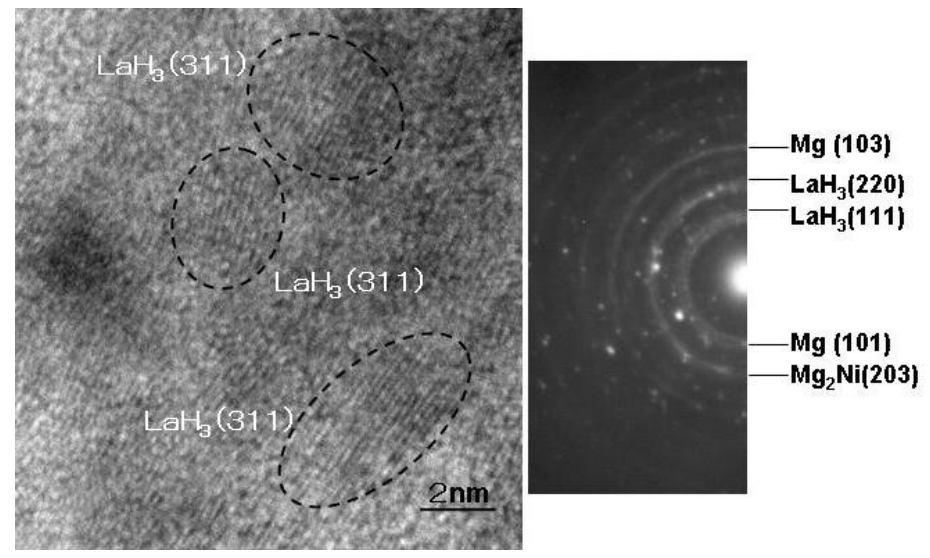

Figure 22. HRTEM image and its ED pattern of dehydrogenated $\mathrm{Mg}_{85} \mathrm{Ni}_{10} \mathrm{La}$ a alloy.

The Mg-K edge image likewise represents the $\mathrm{MgH}_{2}$ phase, and it is clearly recognized that the $\mathrm{MgH}_{2}$ phase provides bright regions common to both the $\mathrm{H}$-plasmon and the $\mathrm{Mg}-\mathrm{K}$ edge in these pictures. Likewise, the $\mathrm{Ni}-\mathrm{L} 2,3$ and La-M $\mathrm{M}_{4,5}$ images should represent $\mathrm{Mg}_{2} \mathrm{NiH}_{4}$ and $\mathrm{LaH}_{3}$ phases, respectively. Both these phases, observed as bright particles of roughly $10 \mathrm{~nm}$ in size, give rise to dark-grey or light-grey spots in the H-plasmon and $\mathrm{Mg}-\mathrm{K}$ images. However, owing to a rather poor energy resolution employed in the present EELS mapping, the Ni-L2,3 and La-M4,5 absorption edges are not necessarily well discriminated from each other and certain overlapping generally occurs, resulting in providing nearly similar patterns of phase distribution in the present pictures. To avoid the confusion involved in 
specifying the $\mathrm{Mg}_{2} \mathrm{NiH}_{4}$ and $\mathrm{LaH}_{3}$ hydride nano-grains, a combined use of EELS and HRTEM techniques appears to be important.

Figure 21 shows HRTEM images of the same sample as shown in Fig. 19. The hydride phase of each nano-grain has been identified in such a way that a measured $d$-spacing of lattice planes is consistent with a calculated one of the hydride. In these figures, nanoboundaries formed between $\mathrm{MgH}_{2}$ and $\mathrm{LaH}_{3}$ nano-grains (left) and a small cluster composed of $\mathrm{LaH}_{3}$ and $\mathrm{Mg}_{2} \mathrm{NiH}_{4}$ nano-grains embedded in a matrix of $\mathrm{MgH}_{2}$ nano-grains (right) can be seen.

Figure 22 shows a HRTEM image and its ED pattern of a dehydrogenated $\mathrm{Mg}{ }_{85} \mathrm{Ni}_{10} \mathrm{La}$ alloy. After the dehydrogenation at $300^{\circ} \mathrm{C}$, the alloy transforms into a structure composed of $\mathrm{Mg}$ and $\mathrm{Mg}_{2} \mathrm{Ni}$ metallic phases together with the $\mathrm{LaH}_{3}$ hydride phase remaining unchanged. This phase structure is consistent with the XRD result shown in Fig. 2. Although the grain growth of $\mathrm{Mg}$ nano-grains is suppressed during the dehydrogenation, coarsening of $\mathrm{Mg}_{2} \mathrm{Ni}$ nano-grains is often observed by HRTEM. It is reflected on the ED pattern as a continuous diffraction ring of $\mathrm{Mg}$ and a spotty one of $\mathrm{Mg}_{2} \mathrm{Ni}$.

\section{In situ TEM-EELS studies of dehydrogenation process}

It is interesting to observe the hydrogen desorption process at elevated temperatures directly in the electron microscope. For this purpose, a hydrogenated sample is deposited on a tungsten wire of $25 \mu \mathrm{m}$ in diameter and heated by passing an electric current under a vacuum of $10^{-5} \mathrm{~Pa}$ in the microscope. The temperature of the sample is determined from the current using a calibrated curve with an accuracy of about $\pm 20^{\circ} \mathrm{C}$. Since the sample has been exposed to the air for a few minutes before inserting into the microscope, it inevitably suffers from surface contamination. This may cause a substantial delay of the onset of hydrogen desorption in comparison with those found in the TDS measurements. The desorption process of a hydrogenated sample has been continuously video-recorded for TEM BF and EELS H-plasmon images at a fixed temperature of $\sim 350^{\circ}$ and $\sim 450^{\circ} \mathrm{C}$.

Figure 23 shows a time evolution of a TEM BF image of a hydrogenated $\mathrm{Mg}{ }_{85} \mathrm{Ni}_{10} \mathrm{La}$ a alloy held at $\sim 350^{\circ} \mathrm{C}$. It can be seen from the figure that, a few minutes later from the start, a bright spot appears at a central part of the sample, goes on extending outwards with the holding time, and covers almost the whole area at the final stage of the heating. This change of the BF image just corresponds to the thermal desorption of hydrogen from the observed area. In fact, the ED patterns taken before and after the heating indicate that, while the sample is composed of nano-grains of $\mathrm{MgH}_{2}, \mathrm{Mg}_{2} \mathrm{NiH}_{4}$ and $\mathrm{LaH}_{3}$ hydrides before heating, it changes into the structure consisting of metallic $\mathrm{Mg}$ and $\mathrm{Mg}_{2} \mathrm{Ni}$ nano-grains in addition to the $\mathrm{LaH}_{3}$ hydrides, as shown in Fig. 24. Although some grains appear to undergo coarsening during the heating, the others stay mostly in the nano-size range at this temperature.

The desorbing process has also been pursued by observing an EELS H-plasmon image at $\sim 450^{\circ} \mathrm{C}$ for the same alloy as above. Its change with the holding time is shown in Fig. 25. It can clearly be seen from the figure that the hydrogen desorption which is initiated on an 
edge side of the sample soon after the heating proceeds into the interior region, and finally covers the whole area of the sample. A bright region corresponding to an $\mathrm{MgH}_{2}$-enriched zone initially extends throughout the sample, but it tends to shrink with the progress of desorption, and is finally replaced by a dark region completely. This change indicates that the $\mathrm{MgH}_{2}$ matrix has been altered to a metallic $\mathrm{Mg}$ matrix by desorbing hydrogen.
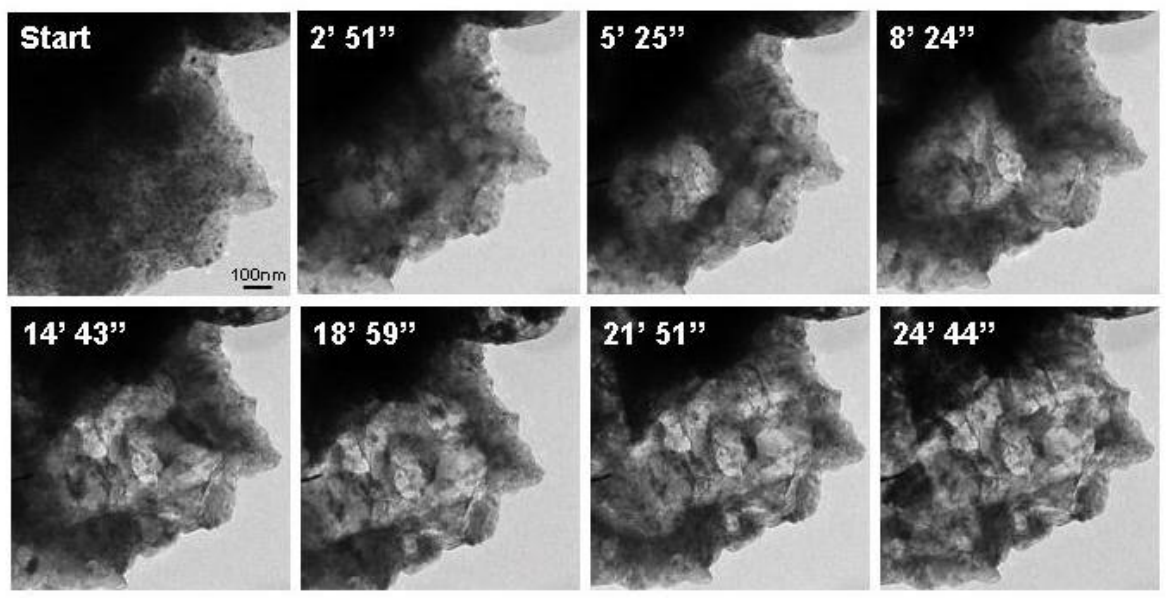

Figure 23. Time evolution of a BF image of a hydrogenated $\mathrm{Mg}{ }_{85} \mathrm{Ni}_{10} \mathrm{La}$ a alloy during heating at $\sim 350^{\circ} \mathrm{C}$.
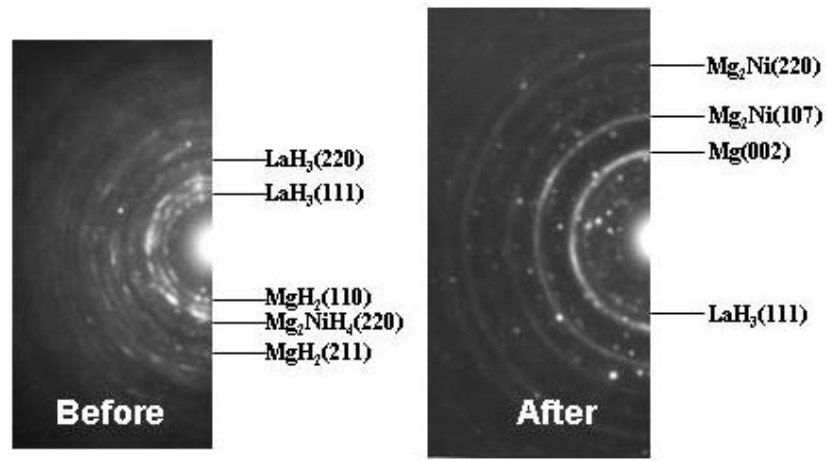

Figure 24. ED patterns of the same sample as in Fig. 23 taken before and after heating at $\sim 350^{\circ} \mathrm{C}$.

Figure 26 shows BF images and the corresponding ED patterns of the same sample as above before and after the heating at $\sim 450^{\circ} \mathrm{C}$. Before heating, fine dark-grey particles corresponding to $\mathrm{LaH}_{3}$ and $\mathrm{Mg}_{2} \mathrm{NiH}_{4}$ hydrides are uniformly distributed in the matrix of $\mathrm{MgH}_{2}$ throughout the sample. This structure has changed drastically after heating. These fine particles have undergone redistribution and reconstruction forming coarse aggregates or precipitates of metallic $\mathrm{Mg}_{2} \mathrm{Ni}$ and $\mathrm{La}$ in the metallic $\mathrm{Mg}$ matrix. The ED pattern taken after heating exhibits strong diffraction spots lying along weak continuous rings of $\mathrm{Mg}$, $\mathrm{Mg}_{2} \mathrm{Ni}$ and La, indicating that a majority of these metallic nano-grains has undergone the 
grain growth at the end of the heating. All these features have also been well recognized in the corresponding EELS images (Tanaka et al., 2009).
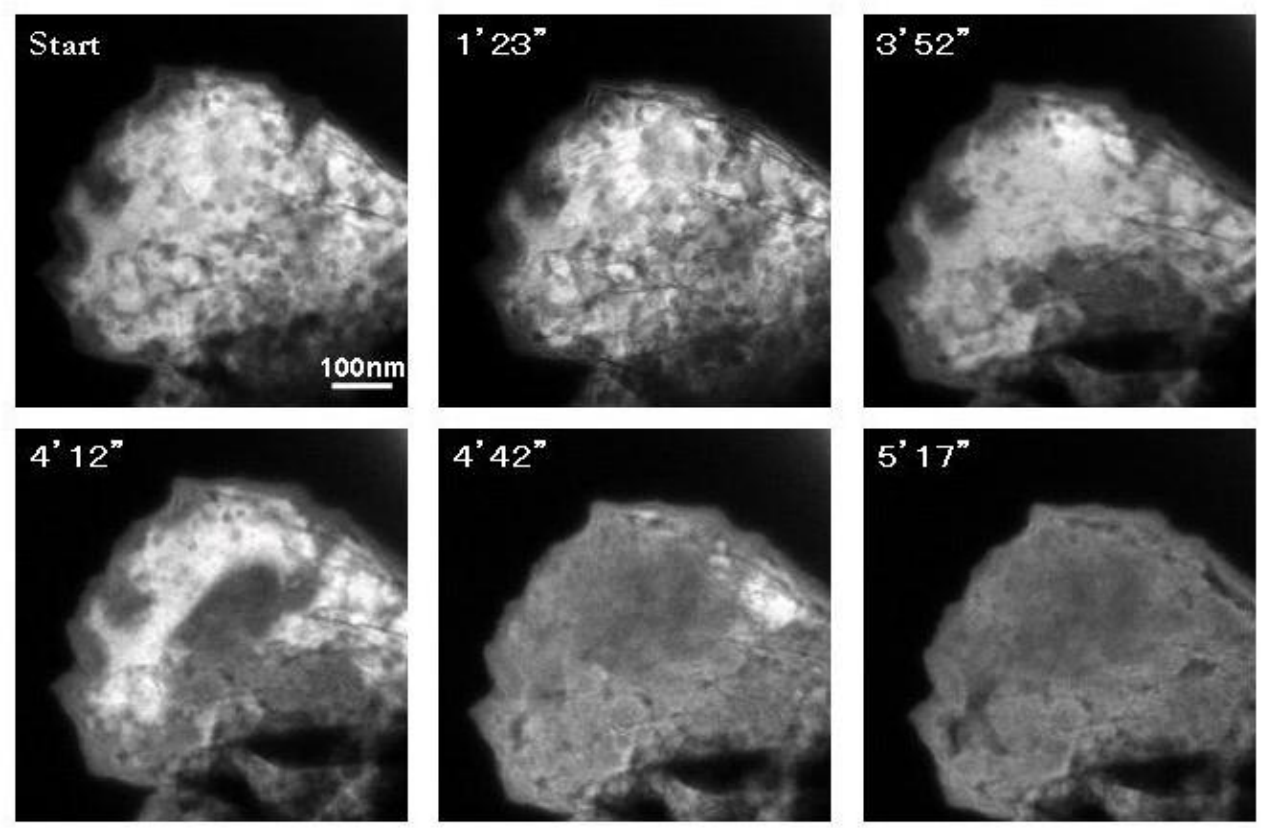

Figure 25. Evolution of EELS H-plasmon image of hydrogenated $\mathrm{Mg}_{85} \mathrm{Ni}_{10} \mathrm{La} 5$ alloy with holding time at $\sim 450^{\circ} \mathrm{C}$. (Tanaka et al., 2009)

Figure 27 shows a HRTEM image of the sample subjected to the heating at $\sim 450^{\circ} \mathrm{C}$, showing a spheroidal $\mathrm{Mg}$ grain grown to $\sim 20 \mathrm{~nm}$ in size together with smaller $\mathrm{Mg}_{2} \mathrm{Ni}$ and La grains in the close vicinity of the $\mathrm{Mg}$ grain. A HRTEM image of a rod-shape La grain grown to $\sim 50$ $\mathrm{nm}$ in length has also been observed (Tanaka et al., 2009).

The TEM-EELS results presented above clearly show that the nano-crystalline hydrides are really formed by hydrogenation and are completely decomposed by heating up to $\sim 450^{\circ} \mathrm{C}$ in the melt-spun $\mathrm{Mg}_{85} \mathrm{Ni}_{10} \mathrm{La}_{5}$ alloy. These results are, however, in contradiction to recent TEM studies (Hanada et al., 2008; Porcu et al., 2008), which claim that $\mathrm{MgH}_{2}$ is readily decomposed to $\mathrm{Mg}$ even at room temperature by the electron beam irradiation during observation. In these studies, ball-milled $\mathrm{MgH}_{2}$ sample doped with $\mathrm{Nb}_{2} \mathrm{O}_{5}$, which exhibits excellent hydrogen reactivity, is used in contrast to our melt-spun ternary alloy. A difference in the hydride stability between the two samples may have caused these contradictive results. Another aspect of discriminating the ball-milled sample from the melt-spun alloy is that a thermally unstable hydride, $\gamma-\mathrm{MgH}_{2}$, is amply formed and mixed with the stable hydride, $\beta-\mathrm{MgH}_{2}$, by ball milling (Danaie, 2010). Such an unstable hydride is not formed in the melt-spun alloy. It must also be taken into account that our powder sample used for the TEM-EELS studies is inevitably contaminated with oxygen on the surface before it is 
inserted into the electron microscope. This may have prevented the desorption of hydrogen from the sample and hence the decomposition of hydrides during the observation. Further studies are necessary to clarify these points.
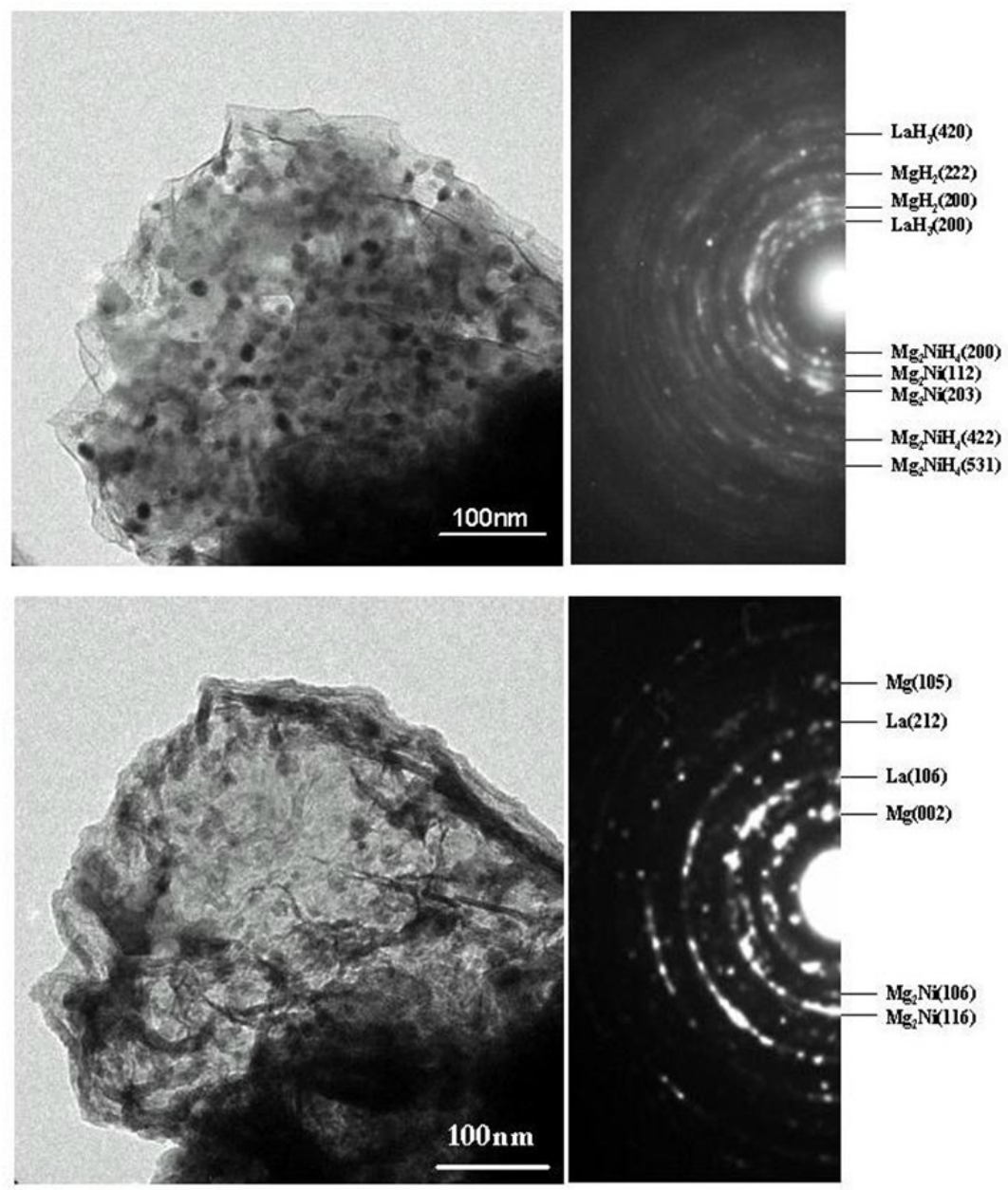

Figure 26. BF images and ED patterns of the same sample as in Fig. 25 taken before heating (upper) and after heating (lower) at $\sim 450^{\circ} \mathrm{C}$. (Tanaka et al., 2009) 


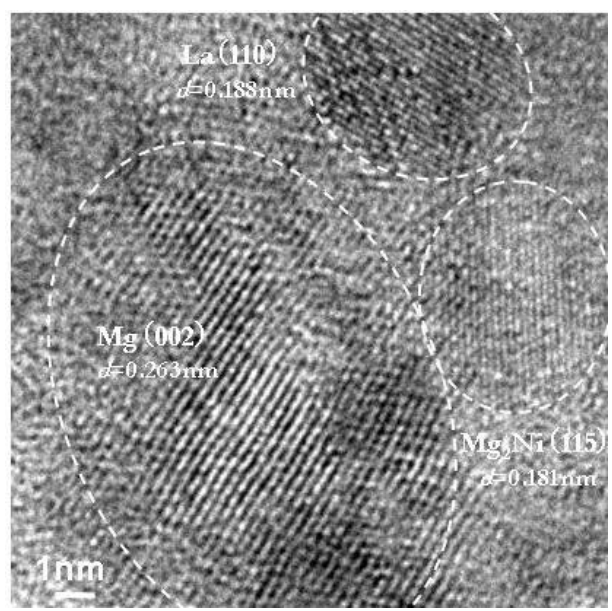

Figure 27. Fig. 26. HRTEM image of the same sample as in Figs. 25 and 26 observed after heating at $\sim 450^{\circ} \mathrm{C}$. (Tanaka et al., 2009)

Finally, we discuss the nature of an EELS plasmon peak in a hydrogenated sample. The EELS plasmon (or H-plasmon) peak observed in this study is considered to be associated with an excitation of bulk plasmons by an incident electron beam in the $\mathrm{MgH}_{2}$ nanograins. This is justified from the similarity between the EELS H-plasmon and $\mathrm{Mg}-\mathrm{K}$ images of the hydrogenated $\mathrm{Mg}_{85} \mathrm{Ni}_{10} \mathrm{La} 5$ sample shown in Fig. 20. The bright region of the $\mathrm{Mg}-\mathrm{K}$ image reflects the $\mathrm{MgH}_{2}$ phase, which just corresponds to the bright region of the H-plasmon image. This bright region of H-plasmon image has been confirmed to disappear completely after the in situ hydrogen desorption, as shown in Fig. 25, although the $\mathrm{Mg}-\mathrm{K}$ image still provides a bright region for the metallic $\mathrm{Mg}$ phase formed (Tanaka et al., 2009).

To prove the interrelation between the EELS plasmon spectrum and the H-plasmon image more closely, we reexamine

the EELS spectrum and the corresponding image of $\mathrm{MgH}_{2}$ using a commercially pure sample, as shown in Fig. 28, where the measured EELS spectra and the corresponding images are compared between the as-received sample $\left(\mathrm{MgH}_{2}\right)$ and the dehydrogenated one (Mg) prepared by in situ heating at $\sim 450^{\circ} \mathrm{C}$. The H-plasmon peak (indicated by arrow) can be clearly seen at an energy-loss $E \sim 11 \mathrm{eV}$ in $\mathrm{MgH}_{2}$, whereas it is almost diminished in $\mathrm{Mg}$. The H-plasmon peak causes a bright image of the $\mathrm{MgH}_{2}$ phase throughout the sample in the former, whereas a dark-grey image of metallic $\mathrm{Mg}$ is left in the latter. Another small peak at $E \sim 22 \mathrm{eV}$, which is detected in every sample studied, is attributable to a plasmon excitation in a thin $\mathrm{MgO}$ layer which covers the sample surface. In the free-electron model, the plasmon energy $E_{\mathrm{p}}$ is given by (Egerton, 1996), 

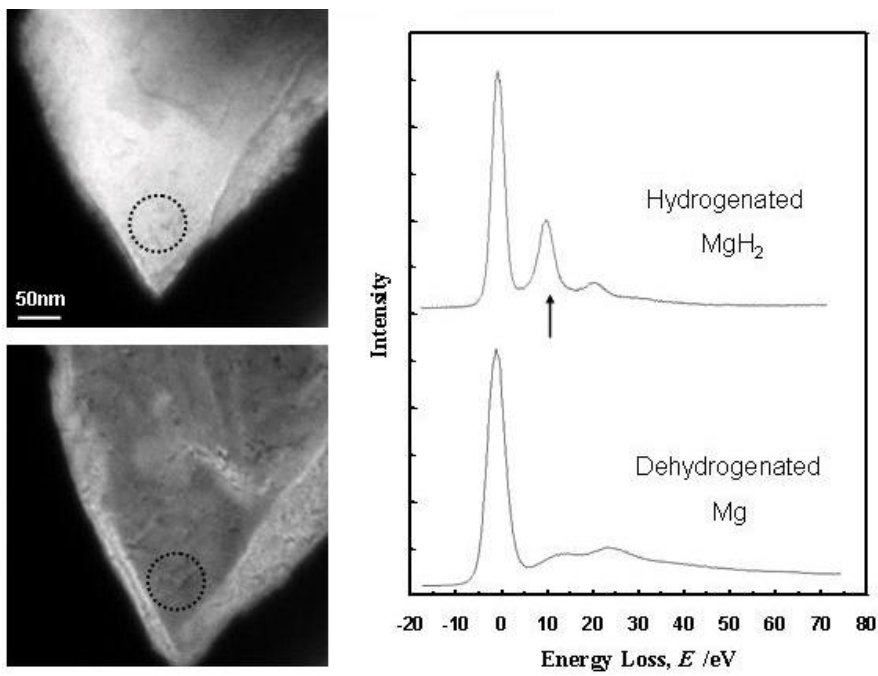

Figure 28. EELS spectra in the low energy-loss region and the corresponding H-plasmon images for $\mathrm{MgH}_{2}$ (upper) and $\mathrm{Mg}$ (lower) for a sample prepared from a commercially pure $\mathrm{MgH}_{2}$ powder. The $\mathrm{H}-$ plasmon peak is indicated by an arrow. The encircled area of the sample shows a spot where the EELS spectra have been taken. (Tanaka et al., 2009)

$$
E_{\mathrm{p}}=\frac{h}{2 \pi} \omega_{\mathrm{p}}=\frac{h}{2 \pi}\left(\frac{n e^{2}}{\varepsilon_{0} m}\right)^{\frac{1}{2}},
$$

where $\omega_{\mathrm{p}}$ is the plasmon angular frequency, $n$ is the electron density, and other quantities have their usual meaning. Taking $n=129.8 \mathrm{~nm}^{-3}\left(\mathrm{MgH}_{2}\right)$ and $428.4 \mathrm{~nm}^{-3}(\mathrm{MgO}), E_{\mathrm{p}}$ is calculated as $13.3 \mathrm{eV}$ and $24.2 \mathrm{eV}$, respectively. These calculated energies approximately agree with the observed ones of the EELS spectra shown in Fig. 28. Now, the plasmon energy for metallic $\mathrm{Mg}$ is calculated as $E_{\mathrm{p}}=10.8 \mathrm{eV}$ taking $n=86.1 \mathrm{~nm}^{-3}$, which falls in the close vicinity of $\mathrm{MgH}_{2}$. However, owing to the lack of energy resolution of the present EELS experiment and/or to the lack of the spectral intensity of the plasmon peak of metallic $\mathrm{Mg}$ in comparison with that of $\mathrm{MgH}_{2}$, this peak has not been clearly detected in the present study. In this respect, it is worthwhile to note that both peaks have been detected in a partially dehydrogenated $\mathrm{MgH}_{2}$ sample subjected to ball milling (Danaie, 2010). An H-plasmon peak similar to our study has also been observed in a ball-milled $\mathrm{NbB}_{5}$-doped $\mathrm{MgH}_{2}$ sample (Kim et al., 2010).

\section{Summary and conclusions}

1. A magnesium-based Mg-Ni-La alloy, specifically Mg85Ni10La5 alloy, prepared by meltspinning and subsequent crystallization annealing exhibits favorable reaction kinetics and PCT characteristics for hydrogen absorption and desorption. The $p-c$ isotherms at $240-330^{\circ} \mathrm{C}$ manifest a flat two-stage plateau with small hysteresis and a maximum $\mathrm{H}$ - 
capacity of $\sim 4.6 \mathrm{wt} . \%$. A temperature as low as $\sim 200^{\circ} \mathrm{C}$ is enough for hydriding and dehydridng the alloy entirely in a moderate time period. XRD results show that a mixed phase structure of $\mathrm{Mg}$ and $\mathrm{Mg}_{2} \mathrm{Ni}$ before hydrogenation, or $\mathrm{MgH}_{2}$ and $\mathrm{Mg}_{2} \mathrm{NiH}_{4}$ after hydrogenation, together with a thermally stable hydride $\mathrm{LaH}_{3}$, is the main source of these excellent hydrogen storage characteristics.

2. The fully hydrogenated alloy exhibits, in general, four TDS peaks $(a \sim d)$. The magnitude and temperature of each peak depend on the specimen history and the heating rate $\left(0.5 \sim 4^{\circ} \mathrm{C} / \mathrm{min}\right)$ for the TDS measurement. Assuming that a quasi-equilibrium condition is established in the specimen, these peaks are attributed to decomposition of $\mathrm{Mg}_{2} \mathrm{NiH}_{4}$ (peak $a$ ), decomposition of $\mathrm{MgH}_{2}$ (peak $b$ ), release from nano-grain boundaries (peak $c$ ), and decomposition of $\mathrm{LaH}_{3}$ (peak $d$ ). The heating-rate dependence of the TDS peak temperature is successfully analyzed on the basis of Kissinger's equation, from which the activation energy for desorption $E_{\text {des }}$ is obtained for each peak. Assuming that the desorption is a surface-controlled process and that $E_{\text {des }}$ is the sum of an adsoption energy $E_{\text {ad }}$ and an effective binding energy $E_{\text {bind }}$ of hydrogen in the alloy, a relationship between $E_{\text {bind }}$ and the formation enthalpy $\Delta H_{\mathrm{f}}$ of a hydride is proposed. From this relationship, the hydrogen dissolved in the nano-boundaries appears to be $\sim 20 \mathrm{~kJ} / \mathrm{mol}$ $\mathrm{H}_{2}$ more stable than in $\mathrm{MgH}_{2}$.

3. The role of $\mathrm{Ni}$ and La for facilitating the hydrogen storage properties of the Mg-based alloy is multifold. Both elements act to promote the amorphization of the alloy by meltspinning and to produce a homogeneous nano-grain structure by crystallization. Nickel forms stable $\mathrm{Mg}_{2} \mathrm{Ni}$ nano-grains, which act as dissociation and recombination catalysts for hydrogen molecules on the surface of the alloy and contribute to enhance the absorption and desorption kinetics of hydrogen. On the other hand, La forms thermally stable $\mathrm{LaH}_{3}$ nano-hydrides, which work to stabilize the whole nanostructure during the hydriding and dehydriding cycles at temperatures below $\sim 350^{\circ} \mathrm{C}$.

4. The improved kinetics of hydrogen absorption and desorption of the alloy is partly due to faster diffusion of hydrogen along the nano-boundaries than through inside the $\mathrm{Mg} / \mathrm{MgH}_{2}$ or $\mathrm{Mg}_{2} \mathrm{Ni} / \mathrm{Mg}_{2} \mathrm{NiH}_{4}$ grains. The relatively fast diffusivity and high solubility of hydrogen in the nano-boundaries will facilitate the hydrogen transport inside the alloy and hence enhance its absorption and desorption rates.

5. It has been confirmed by TEM and HRTEM studies that, after hydrogenation at $300^{\circ} \mathrm{C}$, this alloy exhibits a nanostructure consisting of $\mathrm{Mg}_{2} \mathrm{NiH}_{4}$ and $\mathrm{LaH}_{3}$ nano-particles $(\sim 10$ $\mathrm{nm}$ ) imbedded uniformly in $\mathrm{MgH}_{2}$ nano-grain $(3 \sim 5 \mathrm{~nm})$ matrices. After dehydrogenation at $300^{\circ} \mathrm{C}$, this alloy exhibits $\mathrm{Mg}_{2} \mathrm{Ni}$ and $\mathrm{LaH}_{3}$ nano-particles imbedded uniformly in the $\mathrm{Mg}$ nano-grain matrix. This nanostructure is almost maintained if the hydrogenation and dehydrogenation treatments are performed at temperatures below $\sim 350^{\circ} \mathrm{C}$.

6. If the temperature is raised beyond $\sim 400^{\circ} \mathrm{C}$, the desorbing as well as the absorbing characteristics of the alloy are significantly degraded. The in situ TEM observation during heating at $\sim 450^{\circ} \mathrm{C}$ indicates that the original nanostructure undergoes remarkable redistribution and reconstruction of the alloy phases, in parallel with the decomposition of the hydrides. Instead of a uniform distribution of the hydride 
particles, segregations of coarse precipitates of $\mathrm{Mg}_{2} \mathrm{Ni}$ and $\mathrm{La}$, together with the grain growth of $\mathrm{Mg}$ matrix, take place. These coarsening of the alloy phases and their inhomogeneous redistribution must have retarded the reaction kinetics for hydrogen.

7. We have succeeded in clearly visualizing a global hydrogen distribution in the alloy sample by imaging the EELS plasmon peak (H-plasmon) arising from the $\mathrm{MgH}_{2}$ phase. By using this technique, the thermal desorption process has been directly observed in the microscope. Melt-spun and nano-crystallized Mg-based alloys are quite favorable materials for this kind of studies.

\section{Author details}

Kazuhide Tanaka

Nagoya Institute of Technology, Toyota Physical and Chemical Research Institute, Japan

\section{Acknowledgement}

The author is grateful to Prof. H. Inokuchi, Prof. A. Ikushima and Prof. Y. Ishibashi of Toyota Physical \& Chemical Research Institute for stimulating discussions and comments. He is also grateful to Dr. S. Towata of Toyota Central R/D Laboratories for the collaboration in the PCT measurements and useful advices, to Mr. T. Miwa, Dr. K. Sasaki and Prof. K. Kuroda of Nagoya University for the cooperation in the TEM-EELS studies, and to Dr. M. Yamada and Mr. K. Hibino of Nagoya Institute of Technology for the collaboration in the sample preparation.

\section{References}

Barkhordarian, G., Klassen, T., \& Bormann, R. Effect of $\mathrm{Nb}_{2} \mathrm{O}_{5}$ content on hydrogen reaction kinetics of Mg. Journal of Alloys and Compounds, Vol. 364, (2004), pp. (242-246)

Danaie, M., Tao, S.X., Kalisvaart, P., \& Mitlin, D. Analysis of deformation twins and the partially dehydrogenated microstructure in nanocrystalline magnesium hydride $\left(\mathrm{MgH}_{2}\right)$ powder. Acta Materialia, Vol. 58, (2010), pp. (3162-3172)

De Negri, S., Giovannini, M., \& Saccone, A. Phase relationships of the La-Ni-Mg system at $500^{\circ} \mathrm{C}$ from 0 to 66.7 at.\% Ni. Journal of Alloys and Compounds, Vol. 397, (2005), pp. (126-134)

Egerton, R.F. (1966). Electron Energy-Loss Spectroscopy in the Electron Microscope (2 ${ }^{\text {nd }}$ edition), Plenum, ISBN 0-306-45223-5, New York

Fernandez, J.F., \& Sanchez, C.R. Rate determining step in the absorption and desorption of hydrogen by magnesium. Journal of Alloys and Compounds, Vol. 340, (2002), pp. (189-198)

Fukai, Y. (1993). The Metal-Hydrogen System, Springer, ISBN 3-540-55637-0, Berlin, Heidelberg, New York

Hanada, N., Ichikawa, T., Hino, S., \& Fujii, H. Remarkable improvement of hydrogen sorption kinetics in magnesium catalyzed with $\mathrm{Nb}_{2} \mathrm{O}_{5}$. Journal of Alloys and Compounds, Vol. 420, (2006), pp. (46-49)

Hanada, N., Ichikawa, T., \& Fujii, H. Hydrogen absorption kinetics of the catalyzed $\mathrm{MgH}_{2}$ by niobium oxide. Journal of Alloys and Compounds, Vol. 446-447, (2007), pp. (67-71) 
Hanada, N., Hirotoshi, E., Ichikawa, T., Akiba, E., \& Fujii, H. SEM and TEM characterization of magnesium hydride catalyzed with $\mathrm{Ni}$ nano-particle or $\mathrm{Nb}_{2} \mathrm{O}_{5}$. Journal of Alloys and Compounds, Vol. 450, (2008), pp. (395-399)

Kim, J.W., Ahn, J.P., Kim, D.H., Chung, H.S., Shim, J.H., Cho, Y.W., \& Oh, K.H. In-situ electron microscopy study on microstructural changes in $\mathrm{NbF}_{5}$-doped $\mathrm{MgH}_{2}$ during dehydrogenation. Scripta Materialia, Vol. 62, (2010), pp. (701-704)

Liang, G., Huot, J., Boily, S., Van Neste, A., \& Schulz, R. Catalytic effect of transition metals on hydrogen sorption in nanocrystalline ball-milled $\mathrm{MgH}_{2}-\mathrm{Tm}(\mathrm{Tm}=\mathrm{Ti}, \mathrm{V}, \mathrm{Mn}, \mathrm{Fe}$ and Ni) systems. Journal of Alloys and Compounds, Vol. 292, (1999), pp. (247-252)

Løken, S., Solberg, J.K., Maehlen, J.P., Denys, R.V., Lototsky, M.V., Tarasov, B.P., \& Yartys, R.V. Nanostructured Mg-Mm-Ni hydrogen storage alloy: Structure-properties relationship. Journal of Alloys and Compounds, Vol. 446-447, (2007), pp. (114-120)

Massalski, T.B. (Ed.). (1986). Binary Alloy Phase Diagrams, American Society of Metals, Matals Park, Ohio

Oelerich, W., Klassen, T., \& Bormann, R. Metal oxides as catalysts for improved hydrogen sorption in nanocrystalline Mg-based materials. Journal of Alloys and Compounds, Vol. 315, (2001), pp. (237-242)

Porcu, M., Petford-Long, A.K., \& Sykes, J.M. TEM studies of $\mathrm{Nb}_{2} \mathrm{O}_{5}$ catalyst in ball-milled $\mathrm{MgH}_{2}$ for hydrogen storage. Journal of Alloys and Compounds, Vol. 453, (2008), pp. (341-346)

Spassov, T., \& Köster, U. Hydrogenation of amorphous and nanocrystalline Mg-based alloys. Journal of Alloys and Compounds, Vol. 287, (1999), pp. (243-250)

Tanaka, K., Kanda, Y., Furuhashi, M., Saito, K., Kuroda, K., \& Saka, H. Improvement of hydrogen storage properties of melt-spun $\mathrm{Mg}-\mathrm{Ni}-\mathrm{RE}$ alloys by nanocrystallization. Journal of Alloys and Compounds, Vol. 293-295, (1999), pp. (521-525)

Tanaka, K. Hydride stability and hydrogen desorption characteristics in melt-spun and nanocrystallized Mg-Ni-La alloy. Journal of Alloys and Compounds, Vol. 450, (2008), pp. (432-439)

Tanaka, K., Miwa, T., Sasaki, K., \& Kuroda, K. TEM studies of nanostructure in melt-spun Mg-Ni-La alloy manifesting enhanced hydrogen desorbing kinetics. Journal of Alloys and Compounds, Vol. 478, (2009), pp. (308-316)

Yamada, T., Yin, J., \& Tanaka, K. Hydrogen storage properties and phase structures of Mgrich Mg-Pd, Mg-Nd and Mg-Pd-Nd alloys. Materials Transactions, Vol. 42, No. 11, (2001), pp. (2415-2421)

Yamaga, A., Hibino, K., Suzuki, M., Yamada, M., Tanaka, K., \& Ueda, K. Analysis of hydrogen distribution on $\mathrm{Mg}-\mathrm{Ni}$ alloy surface by scanning electron-stimulated desorption ion microscope (SESDIM). Journal of Alloys and Compounds, Vol. 460, (2008), pp. (432-439)

Yin, J. \& Tanaka, K. Hydriding-dehydriding properties of Mg-rich $\mathrm{Mg}-\mathrm{Ni}-\mathrm{Nd}$ alloys with refined microstructures. Materials Transactions, Vol. 43, No. 7, (2002), pp. (1732-1736)

Wiswall, R. (1978) Hydrogen Storage in Metals, In: Hydrogen in Metals II, Alefeld, G. \& Völkl, J (Eds.), pp. (201-240), Springer, ISBN 3-540-08883-0, Berlin, Heidelberg, New York

Zaluska, A., Zaluski, L., \& Ström-Olsen, J.O. Nanocrystalline magnesium for hydrogen storage. Journal of Alloys and Compounds, Vol. 288, (1999), pp. (217-225) 